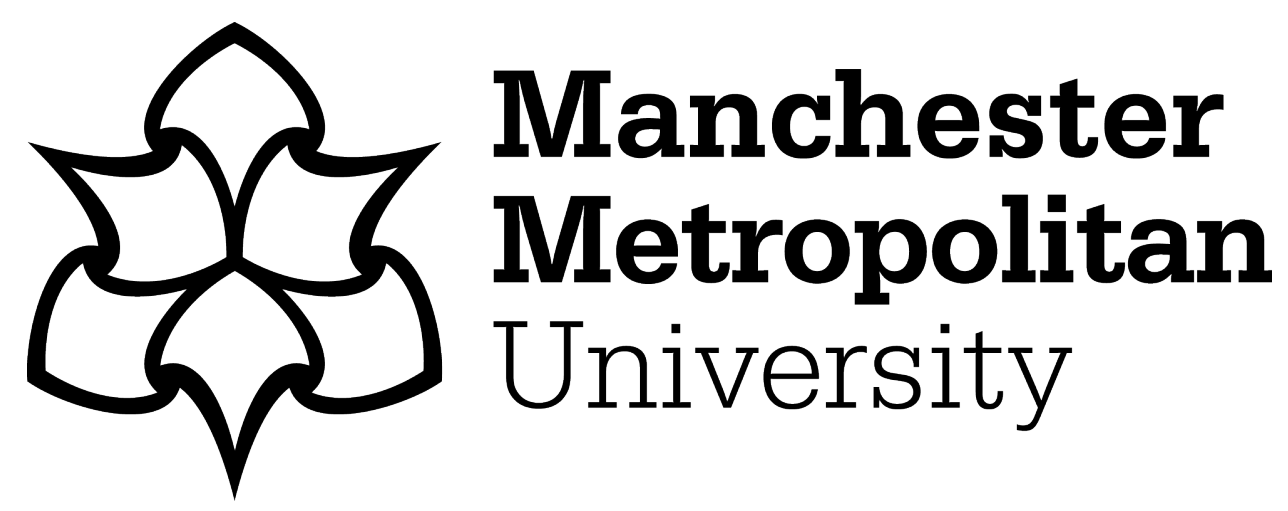

Tóth, Z, Naudé, P, Henneberg, SC and Diaz Ruiz, CA (2021) The strategic role of corporate online references: building social capital through signaling in business networks. Journal of Business and Industrial Marketing, 36 (8). pp. 1300-1321. ISSN 0885-8624

Downloaded from: https://e-space.mmu.ac.uk/627169/

Version: Accepted Version

Publisher: Emerald

DOI: https://doi.org/10.1108/JBIM-02-2020-0101

Usage rights: Creative Commons: Attribution-Noncommercial 4.0

Please cite the published version 


\title{
The strategic role of corporate online references: building social capital through signaling in business networks
}

\author{
Zsófia Tóth \\ University of Nottingham, Nottingham, UK \\ Peter Naudé \\ Manchester Metropolitan University, Manchester, UK \\ Stephan C. Henneberg \\ School of Business and Management, Queen Mary University of London, London, UK, and \\ Carlos Adrian Diaz Ruiz \\ Graduate School of Management, University of Auckland Business School, Auckland, New Zealand
}

\begin{abstract}
Purpose - This paper aims to conceptualize corporate reference management as a strategic signaling activity in business networks. While research has extensively outlined how firms develop and maintain social capital through business-to-business (B2B) relationships, less is known about how they signal their participation in business networks to develop this social capital. Therefore, this paper conceptualizes B2B references, in particular corporate online references (COR), as a tool through which firms "borrow" attractiveness from their business network. Through the lens of structural social capital theory, COR is shown to capture advantages related to interconnectedness between firms.

Design/methodology/approach - The paper reports on a two-step qualitative and quantitative research design. First, the authors undertook a qualitative study that reports on the COR practices of senior business managers. A quantitative study then uses social network analysis (SNA) to audit a digital business network comprising 1,098 firms in a metropolitan area of the UK, referencing to each other through their corporate websites using COR.

Findings - The analyses find that COR practices contribute to building structural social capital in networks through strategic signaling. Firms do so by managing B2B references to craft strategic signals, using five steps: requesting, granting, curating, coding and decoding references. While the existing literature on business marketing portrays reference management as a routine and operational management practice, this investigation conceptualizes reference management, in particular COR, as a strategic activity.

Originality/value - To the best of the authors' knowledge, this is the first study to use SNA to represent B2B references in the form of COR as a network, which overlaps with (but is not entirely identical to) the business network. Further, the study re-conceptualizes reference management as a strategic signaling activity that leverages the firm's participation in business networks to build structural social capital by borrowing attractiveness of prestigious business partners that leverages existing structural social capital. Finally, the paper coins and conceptualizes COR as an exemplar of referencing management and offers propositions for further research.
\end{abstract}

Keywords Business-to-business references, Online references, Reference networks, Testimonials, Social capital, Signaling, Attractiveness, Digital, Networks, B2B references

Paper type Research paper

\section{Introduction}

Business-to-business (B2B) references are positive statements that a business partner issues as testament to a successful business relationship (Aarikka-Stenroos and Makkonen, 2014). In the business marketing literature, reference management is portrayed as a day-to-day actvity that managers perform as a routine, almost an operational chore. The current literature acknowledges the importance of reference management in business practice (Helm and Salminen, 2010), but lacks systematic attention as to how corganizations can leverage reference management as signifyers of existing social capital in business networks (Nahapiet and Ghoshal, 1998; Tsai and Ghoshal, 1998). In fact, reference management is missing from almost every textbook on business marketing (Brennan, 2014; Ellis, 2010), and only a handful of research articles investigate reference management in business marketing (Aarikka-Stenroos and Makkonen, 2014; Jalkala and Salminen, 2010; Hada et al., 2014), despite this being an 
important part of relationship management activities, in particular, relationship initiation capabilities to attract new partners through the use of references (Mitrega et al., 2012; Forkmann et al., 2016). While existing research has focused on a focal firm's reference management practices (Jalkala and Salminen, 2009), further conceptual development is needed to understand reference management in the context of business networks. Consequently, this paper integrates three literature streams, namely, social capital (Eklinder-Frick et al., 2011), reference management in business networks (Aarikka-Stenroos and Makkonen, 2014) and strategic signaling (Spence, 1973; Connelly et al., 2011) to understand how B2B references build social capital.

In business networks, value emerges through relationships and interdependencies that are the result of firms being embedded in such networks. A business network is a set of nodes that connect actors through purposeful relationships (Möller and Halinen, 2017; Ramaswamy and Ozcan, 2020). Business networks include not only organizational customers,

but also suppliers and other stakeholders, because firms form connections through multiple means, including economic transactions, knowledge sharing or informal communications. While most of the existing literature on business networks discusses aspects such as relationship characteristics (Harini and Thomas, 2020), business network dynamics (Brito, 2001) and networking capabilities (Mitrega et al., 2012), we know little about how firms embedded in networks actually build social capital, defined as resources available to actors through connections with others, for example, through shared understanding, norms, knowledge, rules and expectations about patterns of interactions that groups of actors bring to a recurrent activity (Portes, 1998; Coleman, 1988).

This paper investigates social capital from a structural network perspective. Structural social capital is a set of resources embedded within the network and accessed and used by actors within the network (Coleman, 1988; Putnam, 1993). Structural, cognitive and relational social capital are identified as core dimensions of such social capital (Nahapiet and

Ghoshal, 1998; Tsai and Ghoshal, 1998). Social capital is first and foremost structural in that it is created through connectedness and interaction in the network (Burt, 2000; Coleman, 1988; Palmatier, 2008; Villena et al., 2011). Information flows can be increased through strengthened social capital - in both hierarchical organizational relationships as well as in social relations such as friendships - that has structural implications (Adler and Kwon, 2002; Yli-Renko et al., 2001). For example, Portes (1998) theorized that structural social capital - social capital inherent to the structure of relationships regarding who relates to whom and how - can generate competitive advantages. However, the micro-foundations of specific activities remain unclear relating to how structural social capital emanates from as well as leads to the perception of

certain network positions, or how firms can leverage this structural social capital strategically and thus enable the creation of new social capital.

We focus on the activities of organizations whose strategic signals are defined as the purposeful communication of anticipated mental models about the business network (Öberg et al., 2007). In particular, we are interested in how the strategic signals of company attractiveness, based on existing structural social capital, can be used to to instigate new business relationships, and thus new social captial, via reference management as part of relationship initiation capabilities. To do so, this paper conceptualizes corporate online references (COR) as an exemplar for reference management. We define COR as purposeful, strategic signals that firms use to increase their social capital through online channels by purposefully declaring a role and position within a business network. COR appears in the form of textual references (testimonials and case studies) and/or visual forms (logos). COR includes references from customers, suppliers and other types of business partners as well. Overall, this paper is concerned with the following research question:

RQ1. How do firms use references, in particular COR, as strategic signals to leverage their position in business networks to create social capital?

To address the question, we conducted an empirical two-step qualitative-quantitative investigation of reference management practices using corporate websites to form a network-ofreferences indicating who displays B2B references (operationalized as COR) from whom. The network-ofreferences is constituted by actors who are engaged in referencing either as attractive partners who proved to be worthwhile to be associated with, and/or those who use such associations with attractive partners for strategic signaling purposes. Thus, the network-of-references is an important part of the overall business network but does not include all members of it: those that are not involved in references are excluded, and thus the network-of-reference is only a partial representation of the overall network, but homes in on actors with important network positions. Quantitatively, we audit 1,098 firms operating in a major metropolitan area of the UK, focusing on references presented on their corporate websites. Further, the preceeding qualitative study includes in-depth interviews regarding reference management activities of business managers.

This paper contributes to the literature streams on business networks, structural social capital and reference management. First, for business networks, this paper demonstrates that the business network position the firm occupies can constitute a source of attractiveness that firms can leverage through strategic signaling as part of relationship initiation activities. This finding shows that, for example, small firms can become more attractive to prospective buyers by borrowing the attractiveness of larger or more prestigious firms. Second, the study contributes to the extension of business marketing research using social capital theory through an empirical investigation of referencing behaviors. The accumulation of social capital has been demonstrated as important for a firm's success, for instance, in the context of corporate social responsibility (Ferguson et al., 2019) or franchise systems (Watson et al., 2020). This study demonstrates the bridging function of references through signaling that help to close structural holes in the network. Third, for the reference management literature, this study shows that developing B2B references, exemplified through the new conceptualization of COR, constitutes a strategic activity, which means that managers must curate the testimonial evidence required to leverage their network position. 
The remainder of the paper is organized as follows: the theoretical background provides an overview of the business network approach, structural social capital and strategic signaling in reference management. Then, the empirical section introduces the research design, including the two-step data collection via in-depth interviews and social network analysis (SNA). The next section introduces the findings, and a discussion outlines the theoretical and managerial contributions. Finally, the conclusion features limitations and future research directions.

\section{Theoretical background}

We conceptualize reference management, and later COR, by building upon three streams of literature: social capital theory, business networks and strategic signaling (Figure 1). COR in this context serves as an exemplar for B2B references through which we study how firms signal attractiveness in networks and thus attempt to create new social capital through bridging structural holes in the network. Pertinent literature streams that are relevant for this study have some overlaps: signaling attractiveness and achieving certain positions in the network appear both in the business network literature and in the business-related applications of strategic signaling (Öberg et al., 2007); bridging represents an important function of social capital and also a feature of strategic signaling (Eklinder-Frick et al., 2011) and business networks (Mitrega et al., 2012; Thornton et al., 2015); and academic discussions on connectedness and structural holes span both social capital and business networks literature (Ahuja, 2000). In the following subsections, we introduce the three literature streams we draw upon, and we discuss their relevance for, and treatment of, B2B references.

\section{1 "Business network" approach and referencing}

Building upon the research tradition initiated by the Industrial Marketing and Purchasing Group, the business network approach examines the dynamics of interdependences in business relationships. The approach was summarized succinctly by Håkansson and Snehota (1989, p. 256) in the statement that "no business is an island." The approach argues that firms that develop more and better network ties are likely to develop and mobilize more resources than less-connected firms (Lavie, 2006; Mitrega et al., 2012), in line with resourcedependence theory (Pfeffer and Salancik, 2003). According to Möller and Halinen (2017), the research streams on business

Figure 1 The three literature streams for COR's conceptualization

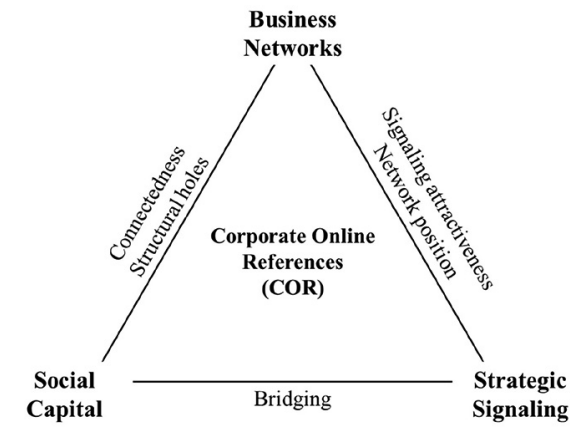

networks cover the following five areas: the dynamics and capabilities of strategic networks (or nets) focusing on how firms can accomplish more by building interdependencies than by going alone (Ellis, 2010); the role of networks in enabling knowledge transfer, learning and co-creation (Araujo, 1998); how managers make sense of their position in the network, including modeling or picturing business network (Abrahamsen et al., 2016; Diaz Ruiz et al., 2020); the relevance of innovation networks in enhancing incremental or radical innovation (Freytag and Young, 2014); and finally an institutional approach to networks (Cheah, 2020), focusing on how groups of actors engage in collaboration and legitimization.

While research has explored the dynamics, capabilities and advantages of business relationships and networks, one aspect that remains vague is how firms signal their (actual or intended) position in the business networks to third parties (Abrahamsen et al., 2012). Whereas research shows that actually achieving an advantageous position within the business network results in competitive advantages (Ford et al., 1996; Mitrega et al., 2012), it has been suggested that even the mere perception of a firm's position in the network affects competitive advantages. For example, a study by Abrahamsen et al. (2012, p. 259) argues that "actors attempt to affect change based on their perceptions of their positions in their network environment," leading them to conclude that "actors' attempts to change their position or role in the network are directed by their subjective sensemaking or perceptions of their surrounding network." Thus, a firm's network position is both an outcome and a driver of successful business relationships; as Anderson et al. (1998, p. 172) conceptualize it, "the position exists as a result of activities performed between actors, while also shaping the modes of action that are expected in connection with the position."

Building upon the notion of perception of network positions by Abrahamsen et al. (2012), we argue that trying to communicate a focal firm's position in relation to business partners, along with the role that the firm plays in the network, can trigger strategic considerations by other firms within the network (such as engaging in new interactions with a firm). One example is displaying publicly multiple connections with actors who are central nodes in the network to trigger the perception that the focal firm is also well-connected, i.e. it resembles a central node. If the mere perception of the business network position affects strategic activities by other actors in the network (Abrahamsen et al., 2012), then the lack of research on what strategies firms can use to communicate or to leverage their business network position for building competitive advantages is an important gap in the business marketing literature. The gap indicates a particular lack of research focusing on relationship initiation. To address this gap, this study posits that one tactic that firms can use to leverage their network position is strategic reference management. It is important to note that the online nature of COR enables a distinct transparency of these reference relationships that is much higher than in more traditional reference networks, and CORs are visible and thus available for a longer time, making them more traceable.

In business marketing, references are marketing communication tools (Jalkala and Salminen, 2009), resulting from existing business relationships (Helm and Salminen, 
2010). A firm's portfolio of references showcases intangible assets in terms of social capital (Jalkala and Salminen, 2010), helping prospective business partners conduct evaluations (Hada et al., 2013; Jaakkola and Aarikka-Stenroos, 2019), by compiling a track record of success stories scattered through the network (Aarikka-Stenroos and Makkonen, 2014). Therefore, references facilitate marketing and sales, in particular, the initiation of new interactions between network actors (Terho and Jalkala, 2017). Most of the existing literature on B2B referencing falls under this literature stream, based on seminal papers that take a network approach to referencing and have a B2B focus (see Table 1, including a positioning of our study in contrast with these sources). The selection criteria for Table 1 were to identify those seminal papers that take a network approach to referencing and have a $\mathrm{B} 2 \mathrm{~B}$ focus. Most of these sources consider the customer as source of the reference (i.e. the referee), with the supplier as receiver (i.e. the signaler) (Aarikka-Stenroos and Makkonen, 2014; Helm and Salminen, 2010; Hada et al., 2014). Also, the potential partners that firms intend to attract through references are primarily conceptualized as customers in these studies (Hada et al., 2014; Helm and Salminen, 2010; Jalkala and Salminen, 2009) or they are not specified (Jalkala and Salminen, 2010). Our study is characterized by a more generalized approach to B2B references that incorporates references not only from customers but also from suppliers as well as other collaborators. Furthermore, most extant studies did not extend their scope to the wider network or, if they did, they restrict their perspective to an ego-network approach (Jalkala and Salminen, 2010) or the study of triads (Jaakkola and Aarikka-Stenroos, 2019). We therefore introduce the concept of a network-of-references to capture this neglected wider perspective, which enables a study of network features such as reciprocity and net borrower status.

\subsection{Structural social capital: referencing facilitates bridging over structural holes}

Structural social capital represents a pivotal dimension of social capital that emerges from the interactions (linkages) in a system or network. Putnam (2000) conceptualizes social capital as the relationship between actors, as well as norms of reciprocity and trustworthiness that are produced in these relationships. The connections between actors form patterns of tasks and processes (Nahapiet and Ghoshal, 1998). Networks including business networks - can be observed through the lens of social capital theory (Bourdieu, 1986). Social capital appears in various forms, with connections between actors embodying structural social capital, which are not limited to immediate connections of an actor but incorporate indirect linkages to actors in the social system (Burt, 2000; Coleman, 1988; Putnam, 1993). To acquire social capital, an actor needs to be connected to others, and therefore, the basis of social capital derives from the composition of direct and indirect linkages.

Eklinder-Frick et al. (2011, 2012) use the concept of (structural) social capital in the context of B2B relationships and highlight that the performance of firms collaborating in networks greatly depends on the strength and accessibility of the social resources and the embeddedness of social capital in the society. Reciprocity is an important feature of the social system: Adler and Kwon (2002) define it as the help provided to others in the prospect of receiving support in return in the future. Informational and social advantages through reciprocity are typically associated with social capital (Tangpong et al., 2016; Lee and Ha, 2018). Nevertheless, besides advantages, there are also risks associated with social capital (EklinderFrick et al., 2011, 2012), for instance, issues that derive from over-embeddedness (Granovetter, 1983).

Bridging and bonding (Putnam, 2000) are vital characteristics of structural social capital. Bridging is the practice of linking actors who were unknown to each other, and related to relationship initiation capabilities (Mitrega et al., 2012), whereas bonding is the strengthening of extant connections. A way firms can connect to new nodes is through bridging to third parties (Thornton et al., 2015), for instance, through alliances (Khoury et al., 2013). Both are pertinent to business networks (Eklinder-Frick et al., 2011). Bonding, however, attracted more research interest so far than bridging and thus requires further attention.

Digital interfaces are increasingly relevant for the development of social capital. There is an interplay between physical and virtual business ecosystems: Web-based technologies can increase the connectedness of location-based communities and accelerate the formation of social capital (Hampton and Wellman, 2003). The bridging function of social capital in digitally enhanced business contexts is described by Nohria and Eccles (1992, p. 304) as early as:

[...the physical] network of relationships serves as a substrate on which the electronic network can float or [...] be "embedded". What the electronic network can do is accelerate as well as amplify the communication flow, but its viability and effectiveness will depend critically on the robustness of the underlying social structure. [...] It is vital to maintain a critical ratio of faceto-face to electronic interactions. It may even be more critical to maintain face-to-face relationships with those [...] who can serve as bridging ties [...]

Thus, theoretical arguments regarding the role of digital interactions, and the overlap between digital and actual business networks was noted 30 years ago, but their empirical investigation became possible only later - our endeavor in this study is to provide an empirical exemplar for this with regards to network-based signaling practices using COR that help to bridge (structural) holes within business networks. Structural holes are gaps in information flows between actors who are situated in the same network but are not directly linked to each other (Ahuja, 2000).

Overall, references can be conceptualized as a "network mobilizer," using Knoke's (1999) interpretation of social capital, that is, the processes of forming and mobilizing actors' network connections within and between firms to gain access to other actors' resources, in line with relationship initiation capabilities (Mitrega et al., 2012). References trigger the mobilization of information, which is an important resource, and facilitate further connections, thereby providing a bridging function (Rajagopal and Sanchez, 2005) in the network. There is, however, a gap in understanding on the ways and structures of how references create new social capital.

\subsection{Actors signal attractiveness through their connections with referencing}

The third stream explains how B2B referencing operates. While the literature streams on business relationships and social capital focus mostly on dyads, B2B referencing operates on a triadic level. Actors signal attractiveness to third parties, based on existing relationships with interaction partners, thus 
enabling new bridged connections. Therefore, B2B references include (at least) three relevant actors. Overall, signaling can be explained by signaling theory that describes how actors make an effort to reduce information asymmetry, because of the fact that actors have access to different types of information ( $\mathrm{Ba}$ and Pavlou, 2002; Connelly et al., 2011). For example, in a job market, jobseekers have a better understading of their own abilities compared to the recruiting firms, which creates asymmetry of information - jobseekers may therefore use their educational credentials to "signal" certain levels of ability to firms. Signaling theory originates in Spence's (1973) work on how signals reduce uncertainty around the productive capabilities of potential employees, including how a degree from a reputable university signals competence to employers. Later signaling research developed around "market signals," including the effects of company attractiveness signals in winning business partners (Celani and Singh, 2009; Ehrhart and Ziegert, 2005). Receivers use signals to construct perceptions of the organizational traits of the sending firm (Collins and Stevens, 2002). Firms can thus increase their attractiveness by sending signals strengthening their image, thereby intending to positively affect how they are perceived by other actors in the network, and thus expanding the number of potentially interested partners (Rynes and Barber, 1990).

Signaling is used strategically by firms when the signaler plans specific actions about how to influence the receiver (Lorange, 1996), intending to elicit a desired response from, for example, suppliers, customers, intermediaries or competitors (Prabhu and Stewart, 2001). Signals are essential for assessing intangible offerings such as services, when the features offered are complex and difficult to assess (Mavlanova et al., 2016). For corporate actors (whether buyers looking for offerings, sellers looking for prospective customers or alliances looking for suitable partners), such signals are critical for comparing available alternatives (Skaggs and Snow, 2004). Reference information is a crucial aspect of building reference portfolios, and provides useful information for relationship management purposes, as demonstrated by Terho and Jalkala (2017) in case of customer references. Relationship management helps the reinforcement of signals toward business partners with certain management practices, such as managing reputation and brand image (Vesal et al., 2020), and reference management can play an important role in this effort.

Signaling theory informs our study because it addresses how signals are used to reduce prevalent information asymmetries that hamper bridging activities, and it has been used in $\mathrm{B} 2 \mathrm{~B}$ reference contexts (Jaakkola and Aarikka-Stenroos, 2019). Signaling can be used strategically to display a firm's access to, or position in a network. For example, firms signal their participation in highly selective business networks by displaying accreditations from professional associations. Coveted accreditations signal high quality and reliability through a sense of exclusivity because few firms can be part of that network, for example, because the entry cost may be prohibitive, or the necessary capabilities are rare (Mavlanova et al., 2012; Williams et al., 2019). Furthermore, "industry awards" (Gallus and Frey, 2017) can be interpreted as strategic signals that demonstrate the positive contribution of a firm in the network. For Öberg et al. (2007), joint ventures are strategic signals intending to communicate close contacts in otherwise separate networks. Thus, firms display signals of interconnectedness, including "business mating" (Wilkinson et al., 2005), to leverage their position in business networks and signal "corporate attractiveness."

Signaling theory explains the (triadic) relationships between the actors involved in the signaling process (Figure 2). This is important because we theorize that managers use references at a network level to generate signals. Based on a signaling theory perspective, and similar to industry awards or accreditatioms, COR therefore provide prospective partners with information that helps with the evaluation of unobservable qualities of the focal firm (e.g. prior experience in relevant industries and position in the business network) - a type of strategic signaling that requires further elaboration.

\section{Research design}

\subsection{Research setting}

We argue that one way to characterize important aspects of a business network is to focus on B2B references (Buttle, 1998; Aarikka-Stenroos and Makkonen, 2014; Cater and Zabkar, 2009), because the references can reveal a particular underlying structure of the network (as perceived as important by the actors within the network). Although previous research exists on modeling or picturing business networks (Abrahamsen et al., 2016), we are not aware of any previous research using $\mathrm{B} 2 \mathrm{~B}$ references to visualize the structure of a business network. While B2B references include verbal recommendations, and written references in the form of emails and other materials, COR is among those few $\mathrm{B} 2 \mathrm{~B}$ references that create a traceable digital footprint, and so this study focuses on them in the empirical investigation as an exemplar. Tracing how B2B references form networks, the actual network positions of firms within such a network-of-references (as a proxy for the business network) can be gauged.

The research design aims at concept development of COR from a business networks perspective, using a two-stage qualitative-quantitative sequence (Miles and Huberman, 1994). The exploratory qualitative phase (Stage 1) leads to the subsequent structural yet still exploratory use of SNA (Stage 2). This design allows the integration of both an in-depth qualitative understanding of COR management and a set of quantitative graph metrics to analyze network properties. We thus follow recent studies in business marketing using such a sequence of semi-structured qualitative interviews and SNA (Eklinder-Frick et al., 2011). We use a proprietary list of members of the trade association in a major city in the UK, as

Figure 2 Strategic signaling through COR

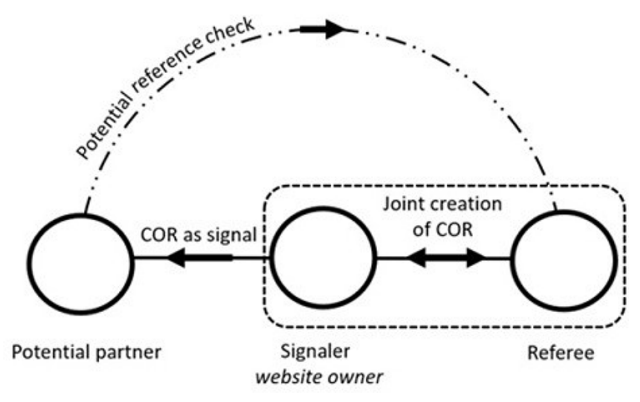


previous research called for establishing clear geographical boundaries to study networks (Ellison et al., 2007). The city trade association facilitated access to its members for both the Stage 1 qualitative interviews on COR management practices, and via its membership database for Stage 2 .

\subsection{Stage 1: reference management practices in the digital environment}

Interviews probed the micro-foundations of the concept of COR by a focal firm. The interviews also explored whether managers monitor references on competitors' websites, and how they use this information for business strategy. The first stage consisted of 12 semi-structured interviews with senior managers from different firms involved in managing COR. The criteria for respondent selection included their relevant expertise (at least three years as a senior manager in the firm) and in-depth familiarity with inter-organizational collaborations as well as line-management remit for COR activities. The firms represent different industries (Table 2). Additionally, subsequent follow-up discussions were organized to corroborate or clarify answers.

The interviews covered the management practices of COR, including the decision-making process regarding which partners to publish on the corporate website, motivations for engaging in COR and perceptions of benefits and costs. Questions also included whether managers checked the COR activity of competitors, and if so, how they acted upon this information. Additionally, interviews included the discussion about COR used specifically by the interviewees' firm looking at their corporate websites and any other previous examples of COR. These visual cues supported the discussions and helped managers to recall their reference management experiences.

Each interview lasted between 30 and $70 \mathrm{~min}$, and was audiotaped and transcribed. The interviews consisted of mostly open-ended questions. A set of "a priori themes" were identified before conducting the interviews to provide the interview building blocks (Crabtree and Miller, 1999), complemented by additional themes emanating from the data (Marshall and Rossman, 1995). The "a priori themes" in the template focused on the benefits and costs of creating COR, motivations and practices of creating COR (for example, which colleagues are part of the process) and how COR could influence attractiveness in networks. For the creation of codes on reference management and general reference-related considerations, we found the works of Jalkala and Salminen (2009, 2010) particularly useful, while for the signaling of attractiveness, we took Öberg et al. (2007) and Hüttinger et al. (2012) as inspiration. We used NVivo to label and structure the data. In the process of building up coding categories, "a priori themes" initially played a guiding role, with some additional codes and themes emerging along the way. We cross-checked and triangulated some of the reported referencing practices from the interviews (for example, pertaining specific collaborations and portfolios of partners) by corroborating the online traces (e.g. by studying corporate websites and online news).

While contemporary studies of digital marketing practices often address social media, for the purpose of this study, we excluded social media and focused on references presented on corporate websites because we were interested in $\mathrm{B} 2 \mathrm{~B}$ practices in which the corporate website operates as the digital shop window. The focal firm has complete control over the content of their corporate website, something that does not apply for all social media interactions. In addition, social media opens avenues for negative, highly critical references (e.g. negative comments or assessments), whereas COR is co-created between partner firms and by nature is always (intended to be) positive.

\subsection{Stage 2: audit of a reference network}

To understand structures of digital practices of reference management, we conducted a quasi-census, auditing 1,098 organizations operating in a major metropolitan area of the UK. This review is close to a geo-fenced census because city regulations made membership of the trade association compulsory until 2013, which means that only recent start-ups are not necessarily part of the database. While the database provided general information, it did not contain any

\begin{tabular}{|c|c|c|c|}
\hline \multicolumn{2}{|c|}{ 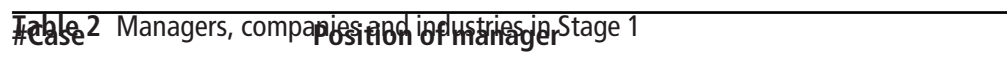 } & \multirow{2}{*}{$\begin{array}{l}\text { Industry } \\
\text { Architectural design }\end{array}$} & \multirow{2}{*}{$\frac{\text { Size }}{\text { Small }}$} \\
\hline 1 & Managing director & & \\
\hline 2 & Managing director & Consultancy & Small \\
\hline 3 & Director of sales & Consultancy & Medium \\
\hline 4 & Head of communications & Education & Large \\
\hline 5 & Head of corporate relations & Education & Large \\
\hline 6 & Online communications director & Electrical equipment & Large \\
\hline 7 & Senior manager, corporate relations & Financial services & Medium \\
\hline 8 & $\begin{array}{l}\text { Senior account manager } \\
\text { (Note: working closely with the communications department) }\end{array}$ & Heavy equipment & Large \\
\hline 9 & Senior sales manager & IT services & Small \\
\hline 10 & Head of business intelligence & Local government & Large \\
\hline 11 & Managing director & Logistics & Medium \\
\hline 12 & Senior manager, corporate relations & Project management & Medium \\
\hline
\end{tabular}

Notes: Size of company is classified by the number of employees, according to UK governmental guidelines aligned with the 2003/361/EC recommendation of the European Commission: a small company is defined as a business below 50 employees, medium between 50 and 250 employees and large as 250 employees and above. The same thresholds are applied for a B2B referencing context by Jaakkola and Aarikka-Stenroos (2019) 
information on references. We thus analyzed the corporate websites of every firm on the list to manually gather information on industry and size, and, crucially, to document which references exist on their website. As a result, the data consisted of 1,002 corporate websites to validate the presence of COR (96 firms did not have corporate websites).

To identify COR management practices, we focused on logos, testimonials and case studies published on corporate websites. Companies rarely include hyperlinks in COR, especially not for embedded logos, testimonials and case studies, thus automated search scripts would reveal only a fragment of data. Therefore, corporate websites were reviewed manually. To ensure that no CORs were missed, domainspecified Google queries additionally included the words "partners," "clients," "customers," "logos," "case studies," "success stories" and "testimonials." The primary COR sections on the websites included "About Us," "Our Partners/ Our Clients," "Case Studies," "What Our Clients/Customers Say" and "Our Expertise." Appendix 1 provides illustrative accounts of the three most common types of COR: partners' logos (often with company names below), testimonials and case studies. Examples of customer references included short client testimonials about the value delivered, for example, in relation to accountancy services. Supplier references appeared, for example, in relation to information technology (IT) systems where the customer firm published references from their IT supplier talking about innovative solutions. References were produced in more formal alliances as well, for instance, research and health-care alliances. Thus, while customer references are part of COR, however, COR includes a wider group of references.

The resulting database included a matrix of signaler (column) and referee (row) where " 0 " meant the "absence of COR" and " 1 " meant the "presence of COR." Thus, we could identify who references whom. From the original database of 1,002 firms, 740 have operational corporate websites and 334 firms listed at least $1 \mathrm{COR}$ on their corporate website, giving an incident rate of firms engaging in COR of 33\%, which is about the same rate as social media usage among UK-based small and medium-sized enterprises (SMEs) $(36 \%$ of SMEs have engaged with using one or more social media platforms; Statista, 2018). While not all firms had websites or presented references, they are still part of the business network, even if they are currently inactive. The reference-connectedness between the active actors in the reference network (based on who provides COR to whom) enables us to explore a networkof-references. Each reference is the digital footprint of a previous business interaction that firms regarded worthy enough to put on public display on their websites.

The data visualization and analysis used UCINET 6, especially NetDraw 2.123, based on SNA to explore structural features of the network. SNA appears in Table 1 in comparison with other methods used for the assessment of networks and relationships, relevant for $\mathrm{B} 2 \mathrm{~B}$ referencing. SNA has its historical roots in graph theory and social capital theory (Sauer et al., 2015). A basic assumption of SNA is that individual actors are embedded in a network of relationships and that social behavior can be studied sufficiently by understanding the structure and some contents of the network (Wellman, 1983). SNA works with the assumption that actors are interdependent, relational ties between actors represent the transfer or flow of resources and that network modeling is possible both from an individual perspective (ego-network) and from a network perspective where structure is created through lasting patterns of relations (Wellman, 1983). The tie represents a relationship that in this study is the COR referral relationship. The nodes in SNA can be individual or organizational actors (in this study, we only assess interorganizational ties). The relational binary matrix (input for the analysis) provides information about the presence or absence of a referral relationship between the firms on the list (Wasserman and Faust, 1994). The relational matrix is asymmetrical - it would only be symmetrical if all references were reciprocal. Thus, the analysis started with fundamental network indices such as average degree, density and reciprocity. The network position of the nodes can be operationalized, for instance, based on the number of ties associated with them, as suggested by Van den Bulte and Wuyts (2007). Further network characteristics such as a structural typology and the identification of popular nodes required the sociogram visualization from NetDraw.

\section{Analysis and findings}

\subsection{Managing practices for business-to-business references}

4.1.1 "Strategic" management of business-to-business references

The qualitative enquiry reveals that firms often include references on their websites as a matter of routine, as opposed to making distinct strategic decisions of selecting which references to display. Embedded logos, testimonials and case stories are often used without much consideration, as part of a middle-management practice. This qualifies other empirical applications of signaling theory (Certo, 2003), as the interviews show that focal firms do not put much thought or strategic consideration in deciding what specific kind of references signal what specific competencies or attractiveness attributes. There were some firms where the strategic elements appear to be stronger, especially with regard to future activities signaled through referencing:

Part of this decision-making process is which are the attractive sectors from where we want to have new clients and which are achievable [...] for example, it is good to be working with industries which are leading edge (Manager \#5).

Targeting changes how COR is managed:

[...] our target markets are supermarkets, distributors who sell to supermarkets and food service companies. So that's restaurants and things. So, I want to develop case studies using customers' success stories from each of those markets (Manager \#12).

However, we did not find evidence of any systematic attempt at maintaining a database or using COR for strategic purposes. Thus, the activity of managing COR may fly under the radar of top management. While all our respondents occasionally (at least once over a period of two years) uploaded references to their websites, surprisingly not a single company included COR as part of their long-term communication plans. Our exploratory research shows that reference management must be characterized as an ad hoc activity rather than a routinized strategic concern. An exception was Company \#11, as they evaluate which references to display on their website biannually following at least a semi-formal group decision-making process. 


\subsubsection{Borrowing attractiveness}

The first impression of a company can be improved by attractiveness borrowed through COR: "initially the things that influence me mostly are what clients they have got, if they reveal that on their website" (Manager \#2). Managers noted that the COR signals associated with a reputable referee mean that the focal company is capable of delivering high-quality offerings, because if their offerings met the expectations of the reputable firm, then they are likely to be of high quality. In other words, if a focal company is "good enough" as a supplier for a reputable firm, then "they must be good anyway" (Manager \#2). When asked about why they spend efforts on managing references on their websites, managers explained that their goal was to "borrow" the attractiveness of a referee, especially their high credibility and visibility, to legitimize and enhance the standing of their own firm. For instance, the managing director of a logistics company discussed the inclusion of a well-known university and a city museum to legitimize his firm:

We put those on the website who have the best reputations and the most attractive logos, the ones people know. So if you are working for those companies [...] Well, for example, the fact that we were working with [City] Museum and [X] University, may sound pretty impressive (Manager \#11).

The relationships with the university and the museum were different types of collaborations that did not fall under the categories of traditional buyer-supplier relationships.

Interestingly, while the goal is sometimes to establish new sales, respondents explained that they also manage references to enhance general reputation. Obtaining direct purchases based on COR appears to be less of an intended benefit, but it does occur. For example, an architectural design firm (Company \#1) was asked whether they could create a similar design to that which they did for their referee, a local warehouse, as is demonstrated in the COR case study on their website. Respondents across different firms revealed a sense of reciprocity in extending and accepting references in a business relationship, with potential relational benefits. "If you did this gesture of goodwill [providing the reference], they are more likely to act favorably towards your company" (Manager \#7), or "we put them on our website, so they have the right to expect something from us along the road" (Manager \#4). Reciprocity between referee and signaler is normally not enacted via reciprocated COR, but through other relational activities.

Some limitations of COR were also identified in our interviews, such as the lack of willingness to provide a COR for specific partners, even if they did an excellent job. For instance, one of the interviewees, who worked on a successful crisis management project, explained why they faced difficulties in receiving COR from referees: "Look, you may get marvelous counselling services, but do you want your friends and colleagues to know that you need them?" (Manager \#3) and "no one wants share that they attended a brilliant anger management training" (Manager \#5). Besides the sensitive nature of some of the business relationships, organizational inertia and intellectual property or patent rights were mentioned as barriers to receiving references and thus using COR.

\subsubsection{Signaling future intentions}

Almost every respondent used a variation of the notion of commercial signals when discussing COR, including metaphors such as "shop window," "banners," "advertising" or "notifications." For example, the managing director of a consultancy firm explained the importance of COR to validate claims in sales pitches: "[...] people go on your website to check you out. Sometimes it is about whether you exist or what you said about what you are doing and with whom is true" (Manager \#3). In other words, even if firms do not use COR as part of their strategic communication efforts, the recurring idea is that displaying COR is an essential signal as they improve visibility akin to a shop window: "Our corporate website is like a shop window, it matters what you put in it. We want the best referrals there" (Manager \#7).

One of the respondents explained: "online referencing is like shouting to the world that we are working with them and we are looking at keeping that interaction as well" (Manager \#2). To do so, managers upload a portfolio of the logos of previous business partners as meaningful signals; as one of the managers pointed out:

If we show the logos, it gives life to the whole thing, because it gives recognition. Even if they do not know who it is, they see the differences in the logos (Manager \#3).

However, signals can also have a negative connotation, as the founder of a small company explained: he was reluctant to upload the logo of his only client fearing that having only one client would give away how small his practice is. This respondent emphasized that he intended to upload references to the website as soon as a portfolio of partners exists:

Honestly, we would love to use referrals, but I feel we need to wait till we have at least three of them [...]. It would not reflect well on us if we put only that sole client on our website.

It appears that firms may refrain from publishing COR on their website when they consider the available referees not numerous enough. On the contrary, some firms wish to avoid appearing to be too big:

I don't ever want to be the biggest customer [. . .] but equally I don't like being the smallest customer because then you could potentially be insignificant. So, I like to be a mid-range customer because this is what keeps businesses going (Manager \#11).

The actual company size and the size the company is striving for are clearly relevant for signaling.

\subsubsection{Gathering market intelligence}

While the Stage 1 analysis shows no evidence that firms manage COR strategically, the interviews reveal that respondents nevertheless routinely monitor references at competitor's websites. In fact, they admit that the competitors' websites are useful to gather information about their ongoing business engagements in what are essentially ad hoc market research exercises (Diaz Ruiz and Holmlund, 2017). One of the managing directors of a logistics firm explained how he uses references as a source of market intelligence: "We actively look at references because we want to know what they do, and whom they work with" (Manager \#11) to better understand the activities and networks of their potential partner as well as competitors. This market intelligence gathering effort via COR did not appear to be restricted to customer references at any of the interviewed firms.

COR for market intelligence has been referred to as a signal about another firm's potential "unattractiveness" (although these can be misleading). For instance, the managing director 
of an architectural design company (Manager \#1) noted that when they had been looking for a partner company for building engineering tasks, they checked corporate websites:

[...] a building engineer in the city put some toilets in the offices of the City Council [...] [...] Then they put them [City Council] on the website which implies that they have done a big work, a big project for the City Council. So, we thought we are just far too small to work with them [. . .] Later on, it turned out that they were trying to work with SMEs like us, but we had already found someone else by that time [...].

In this case, the COR signal by the potential partner was understood in an unfavorable way (in which it was not intended), i.e. poor fit was assumed because of size indicators of the building engineer firm. Also, there were some concerns about the extent to which they can rely on reference information: "[...] that's their perception of what a success story is. [...] The information they disclose is not always $100 \%$ right" (Manager \#8).

\subsection{Stage 2: understanding structures of business-to- business reference networks \\ 4.2.1 Who references whom?}

To probe COR in a more systematic manner, we analyzed a specific network-of-references. There were 1,098 references altogether among the 334 "digitally active" local firms that engaged in B2B COR practices in this network. We used the references to draw a network of interconnected firms that are linked to one another through CORs. Most firms connect as part of a core-periphery structure, which means that a core group of firms in the middle refer to each other more often and therefore possess a more central position (purple dots with high centrality scores in Figure 3) than those at the periphery. Firms on the periphery connect to the core group loosely, normally with only one or two references. Thus, three types of COR network positions exist: the nodes at the core with a high number of incoming references (15\% of those who use references, $n=45)$; peripheral nodes with low COR activity, which mostly give references to core nodes $(n=289,85 \%$ of those who use references); and non-referencing firms $(n=406)$, meaning firms lacking references. Therefore, nodes include only those firms with active references, regardless of whether they are incoming or outgoing.

By mapping who borrows and who lends (credits) references, we can calculate the in-degree and out-degree of firms in the network. In-degree is the number of incoming references from other corporate websites. Out-degree is the number of outgoing references that a focal firm acting as a referee has extended to others, which then appears on the partner's corporate websites. Therefore, if a company uses a high number of references from its partners, its in-degree will be high, while if the firm provides many references to partners that appear on partners' corporate websites, the firm's out-degree will be high. A firm's in-degree is important because it is a proxy for the power of its "COR attractiveness signals." Table 3 summarizes which firms have the highest in-degrees and out-degrees.

The firms with a high in-degree score include the main health-care provider, a law firm and various firms in the construction industry, such as two architecture design firms, an environment consultancy and a firm in construction services. These firms benefit from borrowing the perceived attractiveness

Figure 3 A local reference network

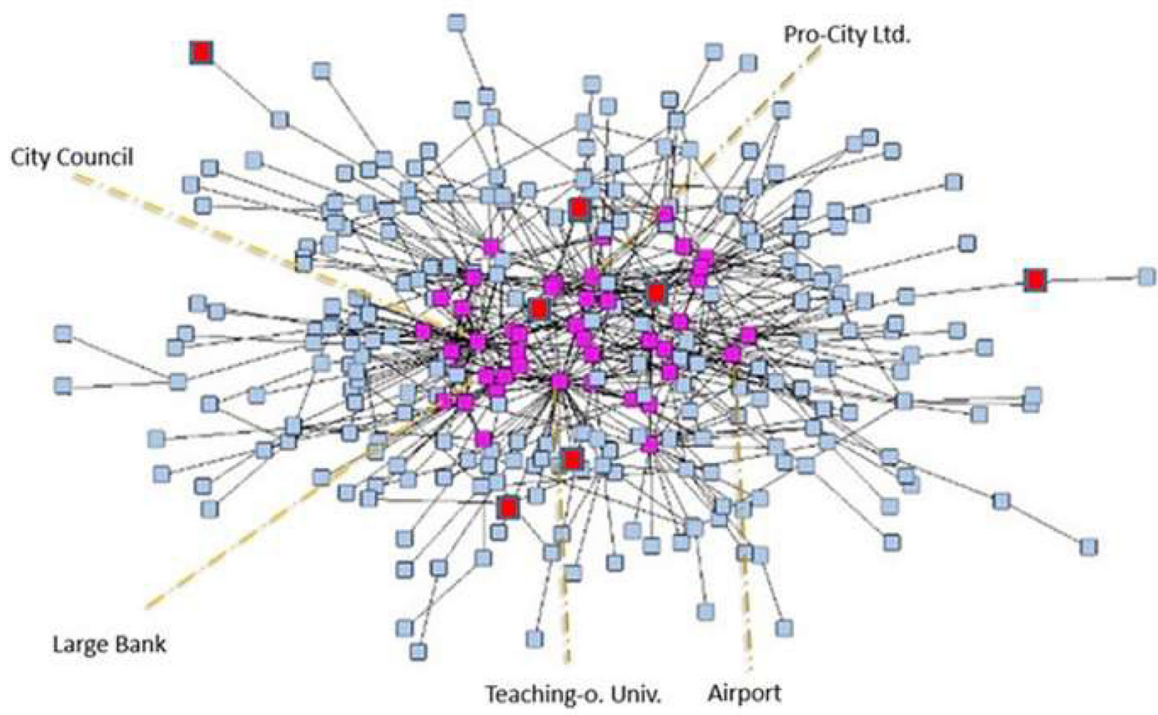

Note: A total of 334 companies (nodes) and 1,098 referrals (ties) are represented by this graph. Unconnected actors and dyads are not presented. Companies represented by purple squares belong to the group of companies with high centrality and companies represented by blue squares have low centrality in the reference network. The categorization was carried out by using principal component analysis. Red squares are the companies where the interviews were conducted; some interviews took place at companies that are members of the local trade companies but are isolated from the core of the reference ecosystem network (and therefore not represented here) 
Table 3 Companies with high in-degrees and high out-degrees in Stage 2

\begin{tabular}{lclc}
\hline & In-degree & & \\
\hline Health-care provider & 22 & Cut-degree \\
Architecture firm specialized in sports architecture & 18 & Health-care provider & 54 \\
Law firm & 14 & Research-oriented university & 53 \\
Local theatre & 14 & Pro City Ltd (business support) \\
Built environment consultancy & 13 & Teaching-oriented university \\
Construction services & 13 & Science park & 24 \\
Research-oriented university & 12 & Airport & 23 \\
Architecture design & 11 & Large bank \\
Hospital charity & 10 & Collaborative group \\
& & (retail and services) \\
Science Park & 10 & Football club & 18 \\
\hline
\end{tabular}

of their business partners. The health-care provider, however, has a more balanced approach in that it also provides a high number of outgoing references. The leading nodes with a high out-degree are, for instance, the city council, health-care provider, a major bank, universities and the football club (Table 3). These nodes have a hybrid footprint in that they include both public and private institutions that are highly visible in the city, with their reputation making them attractive referees.

\subsubsection{How does the reference creditor-borrower balance look like?}

The number of actual reference links compared to the mathematically possible maximum number is low, which means that, as firms only have 1.84 references on average, the network has a low density of links (density 0.002). This network structure can be better explained using an E-I index, which combines in- and out-degree linkages, to measure how nodes form ties in-between firms (Krackhardt and Stern, 1988). The E-I index ranges between $(+1)$ and $(-1)$. A (+1) score indicates that all links are outgoing, a (0) score indicates an equal measure of outgoing and incoming references and a $(-1)$ score means only incoming references. A company that refrains from using COR on their own website (no incoming references, i.e. in-degree of 0 ) but which is attractive for partners as a source of reference and allows partners to publish their reference (various outgoing references, i.e. out-degree +1 ) would have an E-I index of +1 . This company would have an active reference provider or creditor network position, but not be a borrower. A local hospital, for instance, may decide to provide testimonials to all their preferred suppliers and research collaborators but does not seek references from others.

On the other hand, a company that only received references from others (in-degree of +1 ) but did not possess partner firms that have published references from them (out-degree of 0 ) would have an E-I index of -1 . This company would have an active borrower network position. For instance, a small local consultancy firm may seek references from clients and stakeholders following their successful projects and publishes these references on the corporate website, but others do not ask for references from such a small consultancy firm.

Having the same number of incoming and outgoing references would result in an E-I index of 0 - in this network, there were 25 such firms. They give as many references as they borrow and thus have a balanced creditor-borrower network position. Other firms belong to either the "more creditors than borrowers" $(+)$ or "more borrowers than creditors" $(-)$ group without reaching the extreme values of +1 or -1 or the balance of 0 . Appendix 2 provides a sociogram representing directionality in the reference network, i.e. who refers to whom. In essence, the interpretation of the sociogram is that in this particular COR network, nodes appear to develop two types of network roles, the "creditor" of the attractiveness that will have an E-I index close to +1 and the "borrower" with an E-I index closer to -1 . There were altogether 24 firms that were purely "creditors" (with E-I index of +1 ). Table 4 shows the firms with the highest E-I indices. The firms with the highest indegree E-I index, i.e. COR creditors, are mostly non-profit firms. Even the for-profit firms with a high E-I index have a visible public role - a bank, a professional football club and the business development organization.

Nearly two-thirds (185) of the nodes in the network have an E-I index of -1 , which means that they only receive references from other firms (i.e. are exclusively "borrowers"). Based on additional qualitative insights, the active reference borrowing is characteristically driven by the urge to legitimize themselves

Table 4 Out- and in-degrees of selected companies in the core group in Stage II

\begin{tabular}{lccc} 
& Out-degree & In-degree & E-I index \\
\hline City council & 54 & 5 & 0.83 \\
Teaching-oriented university & 23 & 7 & 0.53 \\
Pro City Ltd (business support) & 24 & 8 & 0.50 \\
Airport & 21 & 8 & 0.45 \\
Large bank & 18 & 7 & 0.44 \\
Research-oriented university & 30 & 12 & 0.43 \\
Hospital charity & 10 & 4 & 0.43 \\
Health-care provider & 53 & 22 & 0.41 \\
Football club & 13 & 6 & 0.37 \\
Science park & 21 & 10 & 0.35
\end{tabular}

Notes: The names of companies have been anonymized; out-degree is based on the number of references published at partner companies' corporate websites (COR provided by the focal company; referee); indegree is based on the number of references published at focal company's corporate website (COR used by the focal company; signaler). E-I index is calculated as $(E L-I L) /(E L+I L)$, where EL stands for external links (outdegree) and IL for internal links (in-degree). Hence, for example for the city council the calculation is $(54-5) /(54+5)=0.83$ 
with references from more prestigious firms, but these firms either do not consider or are not in the position of providing COR to others. These firms are mostly SMEs, such as small cafés, restaurants, relocation firms, small solicitor firms and consultancies. The most attractive firms based on how many firms use references from them (i.e. how high their out-degree is) are the city council (54), a large health-care provider (53), two universities (30 and 23), a business support organization run by the local chamber of commerce labeled as Pro City Ltd (24) and the airport (21). However, the in-degree scores of these firms can also be high; meaning that these firms use COR themselves on their corporate website and are thus enhancing their attractiveness via borrowed attractiveness from their referees.

COR can be reciprocal, indicating that two firms are both signaler and referee for each other. We identified 13 such reciprocal dyads, which is particularly low (ca. 1\%). Most firms using reciprocal COR are from the public and non-profit sector, in particular higher education (Table 5).

Qualifying claims in the literature (Portes, 1998), the reference network that we studied shows patterns of organizations typically avoiding the use of reciprocal references, instead there are a few central firms that intensely engage in referencing as referees (i.e. are a source of attractiveness). The low level of reciprocity at the level of referencing practices is striking, yet this does not imply an absolute lack of reciprocity: it may mean that if reciprocity occurs, it takes forms other than providing CORs. For instance, a signaler may display a detailed testimonial from the referee, but instead of reciprocating with their own testimonial, they may decrease their response time to request from this referee, thus improving goodwill.

\section{Discussion}

\subsection{Theoretical contributions}

The theoretical implications of this study are threefold: first, we provide conceptual development of $\mathrm{B} 2 \mathrm{~B}$ references through COR; second, we contribute to understanding the existing literature on business networks and relationships, especially regarding signaling practices and reference management; third,

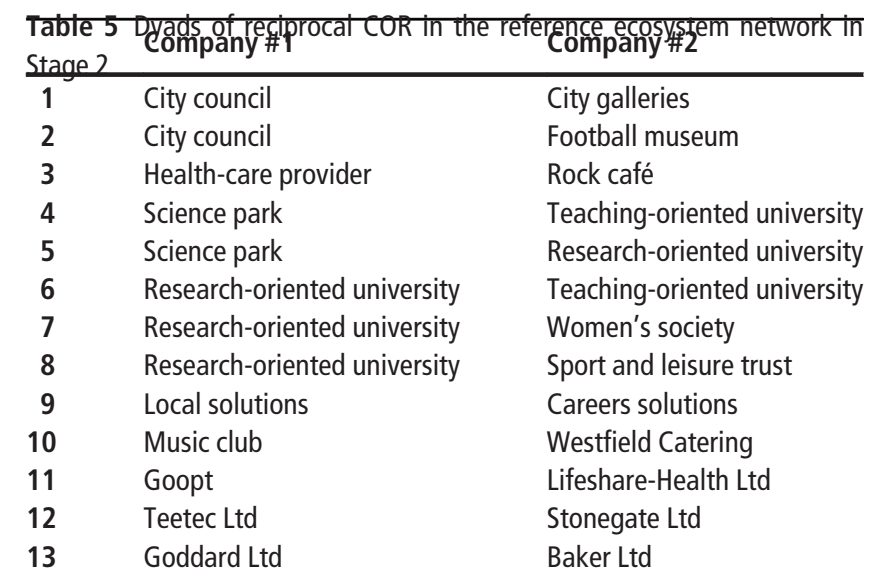

Note: The names of companies have been anonymized we argue that social capital can be accumulated through signaling with references (COR). Social capital studies vary in whether they put emphasis on the "bonding" or "bridging" function of social capital (Eklinder-Frick et al., 2011). One approach that emphasizes primarily the "bonding" function of social capital argues that social capital created in the network consists of tight, reciprocal bonds that exist between most or all members and form as a result of frequent interaction (Coleman, 1988). Reciprocity and shared identity are highly important in this approach (Nahapiet and Ghoshal, 1998). The other approach, emphasizing the "bridging" function of social capital, proposes that social capital arises as people newly connect different networks or parts of networks by bridging structural holes (Burt, 2000). Firms can access greater information and other resources through bridging, along with increased exposure to new opportunities and novel ideas (Burt, 2000). Findings from the interviews (e.g. Manager \#2) suggest that at a perceptual level, "great is who the other great ones call great," which is aligned with what social capital theory suggests about signals being used to bridge the gap of information asymmetry (Eklinder-Frick et al., 2011). The low reciprocity at the level of COR found in the SNA refers to the fact that COR is not typically used for dyadic bonding in the form of crossreferencing (reciprocity has different forms, e.g. COR is reciprocated by increased responsiveness, Manager \#4 and \#7). Literature assumes that reciprocity is a general characteristic of business relationships (Srivastava and Gnyawali, 2011); however, using the example of COR, our study demonstrates that references are typically non-reciprocal and asymmetrical.

This is not to say that "bonding" is entirely irrelevant, as COR indeed has the potential to strengthen the referee-signaler bond, but its primary function appears to be bridging over structural holes and thus to increase the density of the network by borrowing "attractiveness" for relationship initiation activities (Mitrega et al., 2012). It is clearly recognized that firms cannot improve their social capital alone, as Manager \#9 suggests:

[...] you're going to establish your credibility through being recognised externally, not by yourselves, but by others, by winning awards, obviously testimonials by organizations that you're working with in that particular sector. Video testimonials are even better because you can get that across a lot, lot simpler and a lot quicker. And just general case studies.

The notion of interconnectedness demonstrated in this case is in line with social capital theory (Burt, 2000).

Asymmetry implies that firms do not operate as equals regarding industry expertise, product/service and relational qualities (Sharma et al., 1999), which means that some firms ("referees") achieve a more prominent network position than others, and that as "creditors," they lend their attractiveness to their less well-known partners. Our data shows that most firms are net borrowers of attractiveness. Partner selection is a constant network challenge (Hada et al., 2013) and references affect partnering; while this is vaguely mentioned by Hüttinger et al. (2012), it needs further elaboration as provided in our study. Signaling influences the firm's attractiveness as an exchange partner in the business network (Anderson et al., 1994) and COR provides empirical confirmation for this statement. We further contribute to Jaakkola and AarikkaStenroos's (2019) argument by showing that references can 
indeed be more complex than testaments of success, and firms can use them strategically as signals in business markets, showing accomplished success via cooperation within a network of trusted business partners.

The literature often focusses on references in channel relationships, such as a supplier-customer dyad (Hada et al., 2013; Helm, 2003). However, our study finds that several firms use references as testaments of other forms of collaboration, for example, charity work, donations and other pro-bono activities benefiting the public. While some firms display references from customers to demonstrate satisfaction, as expected from the literature, in business markets, firms also provide references for several other reasons, including the signaling of alliances. Kotler's (1972) axiom that "the customer is king" may well apply for business-to-consumer referencing but in case of B2B references, we demonstrate that the supplier and other collaborators can be equally relevant. This study shows that various kinds of collaborations with referees are deemed to be important for referencing, for example, collaborations with non-profit firms, and also that suppliers can also provide references.

We note that while we found extensive use of $\mathrm{B} 2 \mathrm{~B}$ references on corporate websites, actual reference management practices vary significantly, perhaps because normative literature on managing COR is almost non-existent. When it comes to reference management, this study extends the previous literature by detailing three functions of COR:

1 borrowing company attractiveness;

2 signaling future intentions; and

3 gathering market intelligence.

Furthermore, our study provides insights into how COR can unintentionally trigger "unattractiveness" signals. We find that managers are rather serendipitous when determining what references to use, instead of using careful strategic considerations.

To further specify contributions to the literature on business networks, we provide a discussion of different COR-related propositions based on our findings. The development of the propositions is organized according to different network management levels of Möller and Halinen (1999), namely, the dyad ("managing the exchange relationship"), portfolio ("managing a portfolio of relationships") and a wider network level ("managing focal nets and network positions" as well as "managing industries/markets as networks") (Figure 4).

\subsubsection{Corporate online references on the dyadic level}

Firms use COR to increase their company attractiveness by enlisting the standing of third parties, i.e. the referee. While previous research has discussed the concept of company attractiveness (Pulles et al., 2016), our study characterizes a specific aspect of the management of such company attractiveness, i.e. the borrowing of attractiveness via COR. Firms use COR to demonstrate their legitimacy and expertise to stakeholders, including future interaction partners such as corporate buyers and suppliers. Borrowing attractiveness through COR makes a firm more familiar to others in the network in a way that can later be activated:

[...] how you build your testimonial base, your recommendation base, your referral partners [are important]. It makes such a difference when people hear or feel or are touched by what you are doing for people in a way that takes them on a journey and then they buy into you (Manager \#7)

While previous research discussed reputation transfer (Helm and Salminen, 2010), their conceptualization is limited to a dyadic recommendation. Our study shows, however, that firms often play a dual role of being both signaler and referee in a multitude of business interactions, thus demonstrating that firms do not engage in a transactional exchange of references, as previously theorized by Portes (1998). Indeed, we propose that firms use signaling by borrowing the attractiveness of specific types of referees, i.e. often larger partners that typically have a public awareness. Future research could explore industry-specificities and the varying practices that may occur. Our first proposition is as follows:

P1. Firms use COR to borrow attractiveness from business partners.

\subsubsection{Corporate online references on the portfolio level}

Using COR portfolios can elevate the management of B2B references from an ad hoc middle-manager decision to a strategic and organization-wide signaling decision. By showcasing testimonials, case studies and partner logos, the focal firm can signal through the overall COR portfolio an (often anticipated and future-oriented) market position to other firms, and thus clearly indicate the type of business partners that the focal company is looking for. It is worth noting that some COR portfolios carry the risk of degrading the focal firm's attractiveness. Meanings of signals are polysemic and there is evidence for different managers interpreting the same type of COR information differently. For instance, prospective partners can falsely conclude that an company is "out of their league" as a possible partner because of its prestigious COR portfolio, i.e. COR can cause distortions of intended communications. This happened in case of a firm's portfolio of CORs solely from large firms, including the local city council, that gave the impression to an SME manager (Manager \#1) that they would be "punching too far above their weight" if they worked with that partner, even though later it transpired that the company that shared these references was seeking new SME partners. In addition, some managers reported concerns or unwillingness to work with partners that share COR only from large firms because they were seen as "potentially too pricey" or "not very relevant." However, finding only large firms on a potential partner's COR portfolio was rather an advantage for other SME managers, which is an illustrating case for polysemic meanings. As one manager (Manager \#9) explained: "If they were good enough for these large companies, they will probably be good enough for us too." Future research could explore the strategic approaches may vary pertaining to the curation of COR portfolios, along with the underlying reasons as to why some COR portfolios give the "wrong" impression to potential partners (as opposed to what was intended). Considering the findings on configurations of COR partners, the second proposition is:

P2. Firms develop an integrated COR portfolio for signaling purposes. 
Figure 4 COR propositions and different network management levels

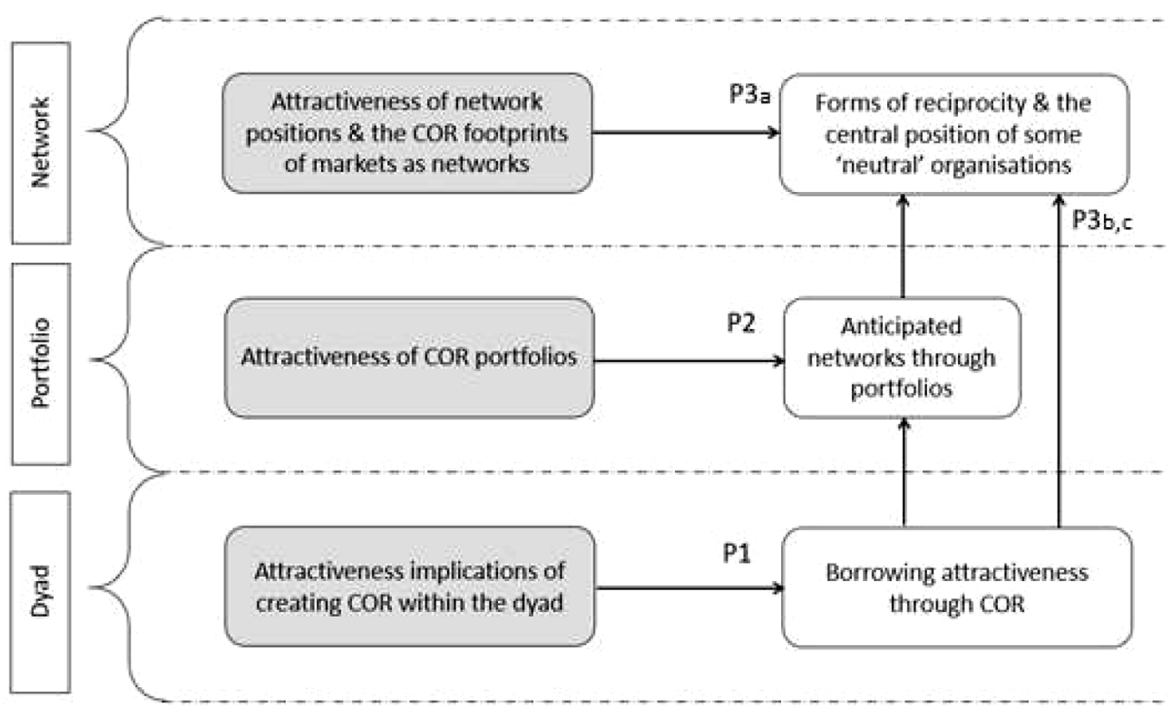

Note: Network management levels (labeled on the left-hand side) relate to Möller and Halinen (1999)

\subsubsection{Corporate online references on a network level}

Reviewing the COR portfolios of potential partners as well as of competitors for market intelligence represents part of strategically managing COR, for example as part of the six market model (Christopher et al., 1991; Payne et al., 2005), where one of the analyzed markets is the referral market. Thus, network morphologies become an important characteristic for understanding such markets, and the position of the focal firm, as well as of other relevant firms in the network provide important insights. Mapping references exhibits a range of business relationships within the network without being able to show the entire network - the only exception would be if all firms were engaged in referencing relationships online, something that our findings indicate is unlikely. A business relationship exists behind each reference (otherwise the reference could not have been produced), but not all business relationships would result in producing references.

As reciprocity is anticipated in most collaborations (Srivastava and Gnyawali, 2011), we expected to find more reciprocal links. Reciprocity helps to create reliance on other firms and ensures that they are required to both give resources to the network and take resources from the network to operate (Batt and Purchase, 2004). This "give and take" is an unwritten rule that is interlinked with company attractiveness (Makkonen et al., 2016). However, our study demonstrates that reciprocity exists only sporadically, at least in the direct form of reciprocated references. This finding was supported by pointing to multiple notions of reciprocity from the qualitative interviews, i.e. the fact that reciprocity is achieved via different "channels" that include goodwill behaviors and other forms of supportive behaviors in return for COR.

The imbalance in referencing is apparent not only because of the scarcity of reciprocated CORs but also because firms in the local reference network studied tend to seek COR instead of providing COR. The average E-I index in our network is -0.63 , showing a tendency toward borrowing attractiveness through COR. An important difference is that the firms with the highest E-I index include some not-for-profit companies that, while being highly visible to the public, do not necessarily represent the most profitable potential business ventures. The favourable network positions of some organizations such as major universities confirm the call by Naudé and Ivy (1999) that established old universities could better exploit their attractiveness and reputational capital. In fact, universities and other popular firms in the reference network can be conceptualized as "organizational opinion leaders" in interorganizational settings. This is an extension of the opinion leadership literature that looks primarily into inter-personal opinion leadership (Flynn et al., 1996) without addressing potential inter-organizational venues. Applying the notion of opinion leaders to inter-organizational settings, such firms can further improve their network positions by proactively providing references for suitable partners, instead of focusing primarily on seeking references. The underlying reasons for the imbalances in COR-specific reciprocity and attractiveness borrowing should ideally be addressed by future studies, along with the similarities and differences between reference and actual business networks.

This discussion leads us to propose the following three propositions:

P3a. The reference network overlaps with, but is not identical to, the wider business network in which firms operate.

P3b. The characteristics of the network include low reciprocity in COR, i.e. those who receive COR do not normally reciprocate by providing $\mathrm{COR}$ to the same firm.

P3c. Most firms are net borrowers of attractiveness through COR. 
Finally, some of the theoretical implications outlined aim at contributing to the application of signaling theory. Although at a theoretical level it has been acknowledged that signaling takes place in networks (Skyrms, 2010), empirical work using signaling theory has mostly focused on dyads (Heide, 2003; Wagner et al., 2011). Thus, providing an empirical case of reference networks illustrates the existence of signaling networks. In fact, we argue that the signaling action through referencing has attractiveness implications at different levels of the business network. While reciprocal COR in interorganizational relationships is not common, other forms of reciprocation may exist. In the markets-as-networks literature, an enduring problem is visualizing networks (Abrahamsen et al., 2012). Some studies shed more light on ways to visualize networks (via managers' subjective mental representations) (Henneberg et al., 2006). This paper extends previous research in the markets-as-networks approach by using SNA to visualize part of an actual network by tracing the digital footprint of references online. By analyzing the reference network as a visualization of B2B references from websites, this study offers a tool for scholars and practitioners interested in studying actual network structures in various markets. The implications for visualizing network structures within the reference network using COR opens avenues for the identification of potential new collaborations. It can also unlock research avenues for comparing the perception that managers have about their networks as proposed by Abrahamsen et al. (2012) with the actual networks as documented in the footprint of their references.

\subsection{Managerial implications}

Our research indicates that managers should consider managing COR strategically and examining dyadic, portfolio and network considerations. In Table 6, we identify some crucial considerations emanating from our research that managers can use to pursue strategic reference management online. These points could also influence management education, for example, in the teaching of B2B marketing and online marketing for future managers.

The first strategic consideration is when and how to request COR. For instance, requesting a reference could happen once a project or transactions has been successfully delivered. However, industrial projects can take years, and industrial offerings often relate to ongoing seller-buyer interactions as part of business relationships. Thus, by the time of completion of a project or a specific offering delivery, some important contact persons in the partner firm may have moved on. Therefore, it is crucial to manage the request for CORs during the project, for example when milestones have been achieved. Another consideration is that in managerial practice, the collection of references often depends on the personal initiative of individuals, such as a key account manager. However, for a strategic management of CORs, it is essential to request references systematically.

A second strategic consideration is when to become a referee, granting references to others. Firms should also consider actively providing references for partners, as this act can strengthen their network position as an influencer or "creditor" of attractiveness. As some actors have more influential network positions than others (Iyengar et al., 2011), firms with high centrality can increase goodwill in the whole network.

The third strategic consideration is about "curating" the collection of references in terms of gathering, updating, selecting and displaying COR for strategic signaling reasons. As museum managers do, business managers should curate their collection of references to align them in terms of ethical standards, values and brand associations. Characteristically, firms update their COR portfolios once every two or three years; we argue that to gain maximum benefit from references implies regular updating as a relevant and productive activity.

Table 6 Strategic considerations on managing COR

\begin{tabular}{|c|c|c|}
\hline $\begin{array}{l}\text { Reference } \\
\text { management practices }\end{array}$ & Strategic considerations & Best managerial practices \\
\hline Requesting & $\begin{array}{l}\text { Selecting the potential referees is a strategic decision } \\
\text { for the signaler. Each type of referee offers strategic } \\
\text { signaling choices }\end{array}$ & $\begin{array}{l}\text { Including COR requests as part of business relationship management } \\
\text { widens the repertoire of references that signalers can choose from as } \\
\text { part of their signaling strategy }\end{array}$ \\
\hline Granting & $\begin{array}{l}\text { While requesting and displaying COR is essential, } \\
\text { companies must also decide if and when to grant } \\
\text { references to other signalers. Becoming a referee can } \\
\text { boost legitimacy in the network }\end{array}$ & $\begin{array}{l}\text { Extend strategic considerations to include granting COR to strategic } \\
\text { partners can increase legitimacy and exposure }\end{array}$ \\
\hline Curating & $\begin{array}{l}\text { The act of collecting, selecting, organizing, updating } \\
\text { and presenting references in a way that best } \\
\text { advances the strategic considerations of the firm }\end{array}$ & $\begin{array}{l}\text { References are organic devices that require updates. Business } \\
\text { managers can become curators of references, identifying when to } \\
\text { mobilize which references for strategic signaling purposes }\end{array}$ \\
\hline Coding & $\begin{array}{l}\text { COR can take multiple forms: testimonials, logo } \\
\text { display, case studies and white papers. Managers } \\
\text { must identify the most compelling devices to encode } \\
\text { signals within the reference }\end{array}$ & $\begin{array}{l}\text { Encode multiple versions of COR (e.g. testimonial, micro-website and } \\
\text { case study) in ways that are accessible not only within website } \\
\text { navigation but also to search engines }\end{array}$ \\
\hline Decoding & $\begin{array}{l}\text { Identifying how competitors and other potential } \\
\text { partners display COR is a source of market } \\
\text { intelligence }\end{array}$ & $\begin{array}{l}\text { Monitor the websites of competitors and prospective clients to scan } \\
\text { for COR. The firm can visualize an important part of their business } \\
\text { network and the network of competitors based on COR provided on } \\
\text { corporate websites. This network mapping can generate insights of } \\
\text { the competitor's strategy }\end{array}$ \\
\hline
\end{tabular}


Coding the number and type of references in a corporate website constitutes the fourth strategic consideration. Usually the minimum number of references in a corporate website appears to be three CORs. Fewer than three references may give the impression that the focal firm is not well-established enough or lacking partners. The type of COR is also important. Displaying logos and supporting visuals (such as pictures of the delivered offerings) is important, but managers should complement these activities with testimonials and case studies.

The fifth consideration is scanning and decoding CORs in competitor's websites, as this benchmarking activity can generate actionable market intelligence (Diaz Ruiz and Holmlund, 2017). By reviewing the COR portfolios of competitors and other (possible) interaction partners as part of market intelligence gathering, managers can learn about the anticipated networks of these firms. Decoding should be carried out carefully; taking into consideration that meanings can be polysemic, with alternative explanations that simultaneously exist. To avoid misunderstandings and potential negative network effects, a review of updated COR portfolios is recommended to gain insights into various possible interpretations. Therefore, a regular company attractiveness audit with regards to COR is recommended.

We reached out to three of the interviewed managers (managers 2, 7 and 9) for reflections and further input on the proposed managerial implications, which allowed us to refine the steps outlined in Table 6 . We recommend the incorporation of these steps as part of an attractiveness audit that would take place ideally once a year. Managers confirmed that the curation of references should indeed be considered at a strategic level and certain features of references are worthy of special attention. For instance, signaling personal touch (i.e. some characteristics about the B2B relationship, such as trusting collaboration), measurable features (such as delivered a project within five months or $99 \%$ client satisfaction rate) and any transferable benefits that may be useful for future partners (this may be industry-specific such as the facilitation of online channel growth as a result of the collaboration) should be considered. Granting references should also be an integral part of reference management because signaling the network position of the referee can generate attractiveness (i.e. being attractive enough for other firms to seek a reference from the referee). The decoding of CORs can be enhanced by a network approach to references, with this study providing a tool for the visualization of the business network through collecting CORs.

In this way firms can learn about the structure and some relational characteristics of their extended network and of their competitors' networks that may help them to make more informed decisions on signaling and the subsequent creation of further social capital. Finally, B2B references are not only from clients to suppliers in the form of client testimonials but include case studies and partner logos as well as a variety of business relationships that can produce references. Also, not only clients provide references but for example, there is evidence for supplier-created references as well as references that resulted from knowledge-sharing partnerships and collaborations with non-profit organizations. COR incorporates all these forms of $\mathrm{B} 2 \mathrm{~B}$ references that are displayed on corporate websites, and firms are encouraged to use these diverse forms and plan for portfolios instead of focusing on customer references only.

\subsection{Limitations and avenues for future research}

This study explores the concept of COR and the role of referencing in strategic signaling to leverage the network position into social capital. As for the originality of the study, it is the first study to examine COR as a valuable touchstone for the creation of social capital as well as a powerful tool to map an important part of the business network. However, no study is without limitations, which are often related to necessary research design choices. One limitation is that we have not obtained reference information from social media platforms. Individual recommendations on social media sites such as LinkedIn may help in exploring inter-organizational connections. Such recommendations and corporate social media sites, however, characteristically present interpersonal social interactions (Yim et al., 2008), whereas COR requires inter-organizational decision-making that goes beyond interpersonal socialization and individual affinity. Nonetheless, social media recommendations may influence company attractiveness in networks, along with various other factors such as word-of-mouth recommendations, industry awards and information gained from financial reports. Future research should address how social capital is created with the help of social media in inter-organizational contexts.

In terms of conceptualization, our reliance on business relationship and network theories is rather narrow. While we see the value of such theories for studying references, prioritizing reference management through the lenses of social capital theory and signaling appeared to be the appropriate conceptual choices to incorporate and to address our research objectives. Combining signaling theory with similar commensurate theories addressing networks could shift the focus of research on CORs toward different kinds of contributions, for example, on relational dynamics or the emergence of the reference network. Future research could study the reference network through the lenses of further network-related theories, and through the incorporation of a longitudinal approach.

Although we have empirical and theoretical grounds on which to base the propositions presented, future research should test them in a variety of business contexts (for instance, across different industries and in different cultural settings) to achieve substantive generalizations. COR can provide managers with an important B2B marketing communication tool to help strengthen their firm's attractiveness. Accordingly, this study may inform an important stream of research on company attractiveness (Mortensen, 2012), because it expands the creation and use of COR to inter-organizational partner selection.

The present study on COR, based on specific choices regarding the research design, is associated with some methodological limitations as well as identifying avenues for future research. First, the list of reference management practices explored is not intended to be exhaustive. Instead, the reference management practices discussed exemplify Möller and Halinen's (1999) network levels for the use of COR, by studying referencing practices at the dyadic, portfolio and network levels. Second, to study the network characteristics of COR, we have chosen a local COR network where the boundaries of the network are defined by the geographical location of the firms in the network, as they are all based in the 
same city in the UK. Local COR networks, however, are possibly linked to each other and have the potential to extend the investigation to international COR networks. Future research should test our propositions and investigate the extent to which the relational and structural patterns of the COR network are reflected in other local or international COR networks. The relational and structural patterns may include how networks change toward becoming more stable or turbulent, drawing on Pfeffer and Salancik (1978) who refer to the existence of reference networks as a stabilizer of local interorganizational relationships:

[in referral networks] we suspect that the frequency and cohesiveness of such networks would increase when competition is high, and communication facilities are available, such as local companies where the parties can get together (pp. 149-150).

In addition, at times not only the existence of links within the network but the lack of these local connections can be important - the notion of structural holes deserves investigation to identify network constraints. We acknowledge the limitation that by mapping a reference network, identifying whether partner firms acted as supplier, customer or another type of partner such as collaborator in a research and development project is often not possible (e.g. while using the "client testimonials" note on the website clarifies roles, using titles such as "testimonials," "our partners" or "case studies" leaves various options open) and therefore we did not specifically look for these roles while collecting network data. Third, our empirical investigation has limited capacity to capture the procedural nature of the creation of references in business relationships and the way COR networks evolve, and future studies could therefore incorporate a time perspective. Future research on reference networks should seek ways of capturing elements of value co-creation, for instance, by applying dynamic network modeling and to identify polysemic meanings, potentially by combining the structural study of networks and configurations of meanings, using a combination of SNA and fuzzy set qualitative comparative analysis. Finally, one of the findings is that managers monitor their competitors' websites to gather market intelligence (Diaz Ruiz and Holmlund, 2017); however, this study only introduced the practice, and more research is needed to understand the extent to which $\mathrm{B} 2 \mathrm{~B}$ references constitute a sort of market intelligence, and how managers make this information actionable. This may include the study of the differential impact of types of COR on the perceived attractiveness of a potential partner.

\section{References}

Aarikka-Stenroos, L. and Makkonen, S.H. (2014), "Industrial buyers' use of references, word-of-mouth and reputation in complex buying situation", fournal of Business $\mathcal{E}$ Industrial Marketing, Vol. 29 No. 4, pp. 344-352.

Abrahamsen, M.H., Henneberg, S.C. and Naudé, P. (2012), “Using actors' perceptions of network roles and positions to understand network dynamics", Industrial Marketing Management, Vol. 41 No. 2, pp. 259-269.

Abrahamsen, M.H., Henneberg, S.C., Huemer, L. and Naudé, P. (2016), "Network picturing: an action research study of strategizing in business networks", Industrial Marketing Management, Vol. 59, pp. 107-119.

Adler, P.S. and Kwon, S.W. (2002), "Social Capital: prospects for a new concept", Academy of Management Review, Vol. 27 No. 1, pp. 17-40.

Ahuja, G. (2000), "Collaboration networks, structural holes, and innovation: a longitudinal study", Administrative Science Quarterly, Vol. 45 No. 3, pp. 425-455.

Anderson, J.C., Håkansson, H. and Johanson, J. (1994), "Dyadic business relationships within a business network context”, Fournal of Marketing, Vol. 58 No. 4, pp. 1-15.

Anderson, H., Havila, V., Andersen, P. and Halinen, A. (1998), "Position and role - conceptualizing dynamics in business networks", Scandinavian fournal of Management, Vol. 14 No. 3, pp. 167-186.

Araujo, L. (1998), "Knowing and learning as networking", Management Learning, Vol. 29 No. 3, pp. 317-336.

Ba, S. and Pavlou, P.A. (2002), "Evidence of the effect of trust building technology in electronic markets: price premiums and buyer behavior", MIS Quarterly, Vol. 26 No. 3, pp. 243-268.

Batt, P.J. and Purchase, S. (2004), "Managing collaboration within networks and relationships", Industrial Marketing Management, Vol. 33 No. 3, pp. 169-174.

Bourdieu, P. (1986), “The forms of capital”, In Richardson, J., Handbook of Theory and Research for the Sociology of Education, Westport, Greenwood, pp. 241-258.

Brennan, R. (2014), Business-to-Business Marketing, Springer, New York, NY.

Brito, C. (2001), "Towards an institutional theory of the dynamics of industrial networks", Fournal of Business $\mathcal{E}$ Industrial Marketing, Vol. 16 No. 3, pp. 150-166.

Burt, R.S. (2000), "The network structure of social capital", Research in Organizational Behavior, Vol. 22, pp. 345-423.

Buttle, F.A. (1998), "Word of mouth: understanding and managing referral marketing", fournal of Strategic Marketing, Vol. 6 No. 3, pp. 241-254.

Cater, B. and Zabkar, V. (2009), “Antecedents and consequences of commitment in marketing research services: the client's perspective”, Industrial Marketing Management, Vol. 38 No. 7, pp. 785-797.

Celani, A. and Singh, P. (2009), "Signaling theory and applicant attraction outcomes", Personnel Review, Vol. 40 No. 2, pp. 222-238.

Certo, S.T. (2003), "Influencing initial public offering investors with prestige: signaling with broad structures", Academy of Management Review, Vol. 28 No. 3, pp. 432-446.

Cheah, C.W. (2020), "Why companies exploit the dual marketing strategy? A network-institutional perspective", Fournal of Business \& Industrial Marketing, Ahead-of-Print, doi: 10.1108/JBIM-05-2019-0205.

Christopher, M., Payne, A.F.T. and Ballantyne, D. (1991), Relationship Marketing: Bringing Quality, Customer Service and Marketing Together, Oxford: Butterworth-Heinemann Publishing.

Coleman, J.S. (1988), "Social Capital in the creation of human capital”, American foumal of Sociology, Vol. 94, pp. 95-120.

Collins, C.J. and Stevens, C.K. (2002), "The relationship between early recruitment-related activities and the application decisions of new labor-market entrants: a brand 
equity approach to recruitment", fournal of Applied Psychology, Vol. 87 No. 6, pp. 1121-1133.

Connelly, B.L., Certo, S.T., Ireland, R.D. and Reutzel, C.R. (2011), "Signaling theory: a review and assessment", fournal of Management, Vol. 37 No. 1, pp. 39-67.

Crabtree, B.F. and Miller, W.L. (1999), "Using codes and code manuals: a template organizing style of interpretation", In: Crabtree, B F., \& Miller, W L. (Eds), Doing Qualitative Research, Thousand Oaks, Sage, 163-177.

Diaz Ruiz, C. and Holmlund, M. (2017), "Actionable marketing knowledge: a close reading of representation, knowledge and action in market research", Industrial Marketing Management, Vol. 66, pp. 172-180.

Diaz Ruiz, C., Baker, J., Mason, K. and Tierney, K. (2020), "Market-scanning and market-shaping: why are companies blindsided by market-shaping acts?", fournal of Business $\mathcal{E}$ Industrial Marketing.

Ehrhart, K.H. and Ziegert, J.C. (2005), "Why are individuals attracted to companies? ", fournal of Management, Vol. 31 No. 6, pp. 901-919.

Eklinder-Frick, J., Eriksson, L.T. and Hallén, L. (2011), "Bridging and bonding forms of social Capital in a regional strategic network", Industrial Marketing Management, Vol. 40 No. 6, pp. 994-1003.

Eklinder-Frick, J., Eriksson, L.T. and Hallén, L. (2012), "Effects of social capital on processes in a regional strategic network", Industrial Marketing Management, Vol. 41 No. 5, pp. 800-806.

Ellis, N. (2010), Business to Business Marketing: Relationships, Networks and Strategies, Oxford University Press, Oxford.

Ellison, N.B., Steinfield, C. and Lampe, C. (2007), "The benefits of Facebook "friends": social capital and college students' use of online social network sites", Fournal of Computer-Mediated Communication, Vol. 12 No. 4, pp. 1143-1168.

Ferguson, J., Brown, B. and Boyd, D.E. (2019), "A conceptualization of corporate social responsibility and moral intensity in the supply chain", fournal of Business $\mathcal{E}$ Industrial Marketing, Vol. 35 No. 3, pp. 602-612.

Flynn, L.R., Goldsmith, R.E. and Eastman, J.K. (1996), "Opinion leaders and opinion seekers: two new measurement scales", fournal of the Academy of Marketing Science, Vol. 24 No. 2, pp. 137-147.

Ford, D., McDowell, R. and Tomkins, C. (1996), "Relationship strategy, investments and decision making", in Iacobucci, D. (Ed.), Networks in Marketing, Sage, New York, NY.

Forkmann, S., Henneberg, S.C., Naude, P. and Mitrega, M. (2016), "Supplier relationship management capability: a qualification and extension", Industrial Marketing Management, Vol. 57, pp. 185-200.

Freytag, P. and Young, L.C. (2014), "Introduction to special issue on innovations and networks: innovation of, within, through and by networks", Industrial Marketing Management, Vol. 43 No. 3, pp. 361-364.

Gallus, J. and Frey, B.S. (2017), "Awards as strategic signals", Fournal of Management Inquiry, Vol. 26 No. 1, pp. 76-85.

Granovetter, M. (1983), "The strength of weak ties: a network theory revisited", Sociological Theory, Vol. 1, pp. 201-233.
Hada, M., Grewal, R. and Lilien, G.L. (2013), "Purchasing managers' perceived bias in supplier-selected referrals", Journal of Supply Chain Management, Vol. 49 No. 4, pp. 81-95.

Hada, M., Grewal, R. and Lilien, G.L. (2014), "Supplierselected referrals", fournal of Marketing, Vol. 78 No. 2, pp. 34-51.

Håkansson, H. and Snehota, I. (1989), "No business is an island: the network concept of business strategy", Scandinavian Fournal of Management, Vol. 5 No. 3, pp. 187-200.

Hampton, K. and Wellman, B. (2003), "Neighboring in Netville: how the internet supports community and social Capital in a wired suburb", City E Community, Vol. 2 No. 4, pp. 277-311.

Harini, K.N. and Thomas, M.T. (2020), "Understanding interorganizational network evolution", Fournal of Business $\mathcal{E}$ Industrial Marketing, doi: 10.1108/JBIM-05-2019-0263.

Heide, J.B. (2003), "Plural governance in industrial purchasing", fournal of Marketing, Vol. 67 No. 4, pp. 18-29.

Helm, S. (2003), "Calculating the value of customers" referrals", Managing Service Quality: An International fournal, Vol. 13 No. 2, pp. 124-133.

Helm, S. and Salminen, R.T. (2010), "Basking in reflected glory: using customer reference relationships to build reputation in industrial markets", Industrial Marketing Management, Vol. 39 No. 5, pp. 737-743.

Henneberg, S.C., Mouzas, S. and Naudé, P. (2006), "Network pictures: concepts and representations", European fournal of Marketing, Vol. 40 No. 3/4, pp. 408-429.

Hüttinger, L., Schiele, H. and Veldman, J. (2012), "The drivers of customer attractiveness, supplier satisfaction and preferred customer status: a literature review", Industrial Marketing Management, Vol. 41 No. 8, pp. 1194-1205.

Iyengar, R., Van den Bulte, C. and Valente, T.W. (2011), "Opinion leadership and social contagion in new product diffusion”, Marketing Science, Vol. 30 No. 2, pp. 195-212.

Jaakkola, E. and Aarikka-Stenroos, L. (2019), "Customer referencing as business actor engagement behavior-creating value in and beyond triadic settings", Industrial Marketing Management, Vol. 80, pp. 27-42.

Jalkala, A. and Salminen, R.T. (2009), "Communicating customer references on industrial companies' web sites", Industrial Marketing Management, Vol. 38 No. 7, pp. 825-837.

Jalkala, A. and Salminen, R.T. (2010), "Practices and functions of customer reference marketing - leveraging customer references as marketing assets", Industrial Marketing Management, Vol. 39 No. 6, pp. 975-985.

Khoury, T.A., Junkunc, M. and Deeds, D.L. (2013), "The social construction of legitimacy through signaling social capital: exploring the conditional value of alliances and underwriters at IPO", Entrepreneurship Theory and Practice, Vol. 37 No. 3, pp. 569-601.

Knoke, D. (1999), "Organizational networks and corporate social capital", In Corporate Social Capital and Liability, Springer, Boston, 17-42.

Kotler, P. (1972), “A generic concept of marketing”, fournal of Marketing, Vol. 36 No. 2, pp. 46-54. 
Krackhardt, D. and Stern, R.N. (1988), "Informal networks and organizational crises: an experimental simulation", Social Psychology Quarterly, Vol. 51 No. 2, pp. 123-140.

Lavie, D. (2006), "The competitive advantage of interconnected companies: an extension of the resource-based view", Academy of Management Review, Vol. 31 No. 3, pp. 638-658.

Lee, C.H. and Ha, B.C. (2018), "The impact of buyer-supplier relationships' social capital on bi-directional information sharing in the supply chain", Fournal of Business \& Industrial Marketing, Vol. 33 No. 3, pp. 325-336.

Lorange, P. (1996), "Interactive strategies - alliances and partnerships”, Long Range Planning, Vol. 29 No. 4, pp. 581-584.

Makkonen, H., Vuori, M. and Puranen, M. (2016), "Buyer attractiveness as a catalyst for buyer-supplier relationship development", Industrial Marketing Management, Vol. 55, pp. 156-168.

Marshall, C. and Rossman, G. (1995), "The substance of the study: framing the research question”, Designing Qualitative Research, pp. 15-37.

Mavlanova, T., Benbunan-Fich, R. and Koufaris, M. (2012), "Signaling theory and information asymmetry in online commerce", Information \& Management, Vol. 49 No. 5, pp. 240-247.

Mavlanova, T., Benbunan-Fich, R. and Lang, G. (2016), "The role of external and internal signals in e-commerce", Decision Support Systems, Vol. 87, pp. 59-68.

Miles, M.B. and Huberman, A.M. (1994), Qualitative Data Analysis: An Expanded Sourcebook, Sage, London.

Mitrega, M., Forkmann, S., Ramos, C. and Henneberg, S.C. (2012), "Networking capability in business relationships concept and scale development", Industrial Marketing Management, Vol. 41 No. 5, pp. 739-751.

Möller, K. and Halinen, A. (1999), "Business relationships and networks: managerial challenge of network era", Industrial Marketing Management, Vol. 28 No. 5, pp. 413-427.

Möller, K. and Halinen, A. (2017), "Managing business and innovation networks - from strategic nets to business fields and ecosystems", Industrial Marketing Management, Vol. 67, pp. 5-22.

Mortensen, M.H. (2012), "Understanding attractiveness in business relationships - a complete literature review", Industrial Marketing Management, Vol. 41 No. 8, pp. 1206-1218.

Nahapiet, J. and Ghoshal, S. (1998), "Social capital, intellectual capital, and the organizational advantage", Academy of Management Review, Vol. 23 No. 2, pp. 242-266.

Naudé, P. and Ivy, J. (1999), "The marketing strategies of universities in the United Kingdom", International fournal of Educational Management, Vol. 13 No. 3, pp. 126-136.

Nohria, N. and Eccles, R.G. (1992), Networks and Companies: Structure, Form and Action, Harvard Business School Press, Boston.

Öberg, C., Henneberg, S.C. and Mouzas, S. (2007), "Changing network pictures: evidence from mergers and acquisitions", Industrial Marketing Management, Vol. 36 No. 7, pp. 926-940.

Palmatier, R.W. (2008), "Interfirm relational drivers of customer value", fournal of Marketing, Vol. 72 No. 4, pp. 76-89.

Payne, A., Ballantyne, D. and Christopher, M. (2005), "A stakeholder approach to relationship marketing strategy: the development and use of the 'six markets' model", European Fournal of Marketing, Vol. 39 Nos 7/8, pp. 855-871.

Pfeffer, J. and Salancik, G. (1978), The External Control of Companies: A Resource Dependence Perspective, Harper \& Row, New York, NY.

Pfeffer, J. and Salancik, G.R. (2003), The External Control of Organizations: A Resource Dependence Perspective, Stanford University Press.

Portes, A. (1998), "Social Capital: its origins and applications in modern sociology", Annual Review of Sociology, Vol. 24 No. 1, pp. 1-24.

Prabhu, J. and Stewart, D.W. (2001), "Signaling strategies in competitive interaction: building reputations and hiding the truth", Fournal of Marketing Research, Vol. 38 No. 1, pp. 62-72.

Pulles, N.J., Schiele, H., Veldman, J. and Hüttinger, L. (2016), "The impact of customer attractiveness and supplier satisfaction on becoming a preferred customer", Industrial Marketing Management, Vol. 54, pp. 129-140.

Putnam, R. (1993), "The prosperous community: social capital and public life", The American Prospect, Vol. 13 No. 4, pp. 249-259.

Putnam, R.D. (2000), “Bowling alone: America's declining social capital", In Culture and Politics, Palgrave Macmillan, New York, NY, pp. 223-234.

Rajagopal, R. and Sanchez, R. (2005), "Analysis of customer portfolio and relationship management models: bridging managing dynamics in a customer Portfolio - Managerial dimensions", Fournal of Business and Industrial Marketing, Vol. 20 No. 6, pp. 307-316.

Ramaswamy, V. and Ozcan, K. (2020), “The 'interacted' actor in platformed networks: theorizing practices of managerial experience value co-creation", fournal of Business \& Industrial Marketing, Vol. 35 No. 7, pp. 1165-1178.

Rynes, S.L. and Barber, A.E. (1990), "Applicant attraction strategies: an organizational perspective", Academy of Management Review, Vol. 15 No. 2, pp. 286-310.

Sauer, N.C., Meinecke, A.L. and Kauffeld, S. (2015), "Networks in meetings: How do people connect", In The Cambridge Handbook of Meeting Science: Cambridge University Press, New York, NY, pp. 357-380.

Sharma, A., Tzokas, N., Saren, M. and Kyziridis, P. (1999), "Antecedents and consequences of relationship marketing: insights from business service salespeople", Industrial Marketing Management, Vol. 28 No. 6, pp. 601-611.

Skaggs, B.C. and Snow, C.S. (2004), "The strategic signaling of capabilities by service companies in different information asymmetry environments", Strategic Organization, Vol. 2 No. 3, pp. 27-29.

Skyrms, B. (2010), Signals: Evolution, Learning, and Information, Oxford University Press.

Spence, M. (1973), Market Signaling: Informational Transfer in Hiring and Related Screening Processes, Harvard University Press, Cambridge, MA.

Srivastava, M.K. and Gnyawali, D.R. (2011), "When do relational resources matter? Leveraging portfolio technological resources for breakthrough innovation", Academy of Management fournal, Vol. 54 No. 4, pp. 797-810.

Statista (2018), Retrieved from www.statista.com/statistics/ 468446/small-and-medium-enterprises-using-social-mediain-the-uk-by-platform/ 
Tangpong, C., Li, J. and Hung, K.T. (2016), "Dark side of reciprocity norm: ethical compromise in business exchanges", Industrial Marketing Management, Vol. 55, pp. 83-96.

Terho, H. and Jalkala, A. (2017), "Customer reference marketing: conceptualization, measurement and link to selling performance", Industrial Marketing Management, Vol. 64, pp. 175-186.

Thornton, S.C., Henneberg, S.C. and Naudé, P. (2015), “An empirical investigation of network-oriented behaviors in business-to-business markets", Industrial Marketing Management, Vol. 49, pp. 167-180.

Tsai, W. and Ghoshal, S. (1998), "Social capital and value creation: the role of intrafirm networks", Academy of Management fournal, Vol. 41 No. 4, pp. 464-476.

Van den Bulte, C. and Wuyts, S. (2007), Social Networks and Marketing, Marketing Science Institute, Cambridge.

Vesal, M., Siahtiri, V. and O'Cass, A. (2020), "Strengthening B2B brands by signalling environmental sustainability and managing customer relationships", Industrial Marketing Management.

Villena, V.H., Revilla, E. and Choi, T.Y. (2011), "The dark side of buyer-supplier relationships: a social capital perspective", Fournal of Operations Management, Vol. 29 No. 6, pp. 561-576.

Wagner, S.M., Coley, L.S. and Lindemann, E. (2011), "Effects of suppliers' reputation on the future of buyersupplier relationships: the mediating role of outcome fairness and trust", Fournal of Supply Chain Management, Vol. 47 No. 2, pp. 29-48.
Wasserman, S. and Faust, K. (1994), Social Network Analysis: Methods and Applications, Cambridge University Press, Cambridge.

Watson, A., Senyard, J. and Dada, O.L. (2020), "Acts of hidden franchise innovation and innovation adaptation within franchise systems", Industrial Marketing Management, Vol. 89, doi: 10.1016/j.indmarman.2020.03.005.

Wellman, B. (1983), "Network analysis: some basic principles", Sociological Theory, Vol. 1, pp. 155-200.

Wilkinson, I., Young, L. and Freytag, P.V. (2005), "Business mating: who chooses and who gets chosen?", Industrial Marketing Management, Vol. 34 No. 7, pp. 669-680.

Williams, Z., Lueg, J.E., Hancock, T. and Goffnett, S.P. (2019), "Positioning through B2B carrier signals: understanding how service quality is communicated via websites", Industrial Marketing Management, Vol. 81, pp. 54-64.

Yim, C.K., Tse, D.K. and Chan, K.W. (2008), "Strengthening customer loyalty through intimacy and passion: roles of customer-firm affection and customer-staff relationships in services", Fournal of Marketing Research, Vol. 45 No. 6, pp. 741-756.

Yli-Renko, H., Autio, E. and Sapienza, H.J. (2001), "Social capital, knowledge acquisition, and knowledge exploitation in young technology-based firms", Strategic Management fournal, Vol. 22 Nos 6/7, pp. 587-613. 


\section{Zsófia Tóth et al.}

\section{Appendix 1}

Figure A1 Three main types of COR: logos, testimonials and case studies

\section{Logos}

Our Partners
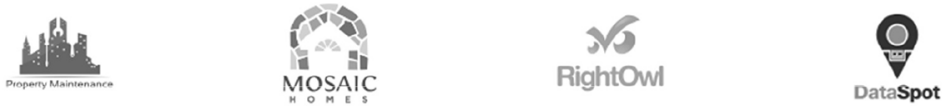

\section{Testimonials}

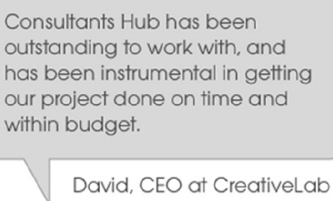

Thanks to Consultants Hub we are now able to quickly and easily execute on our strategies. Without them it appeared to be far too complex to fully implement our campaigns.

Anne, HR Director at EcoAnalyst
We are absolutely delighted to be working with Consultants Hub. Their team members are extremely responsive, friendly and knowledgeable.

Matthew, Creative Director at ClearDesign

\section{Case Studies}

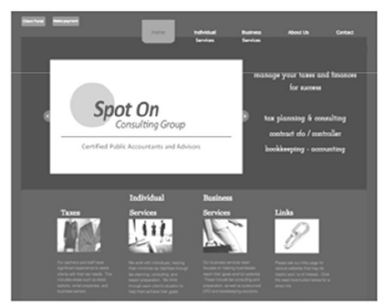

How Consultants Hub helped SpotOnAccountants

Consultants Hub has been working with SpotOnAccountants since 2017, and played a major role in transforming their business processes and improving efficiency. Real-time support from Consultants Hub provides SpotOnAccountants with critical insights into their business to make fast decisions and ultimately their accountancy services became more dynamic in a turbulent marketplace. Consultants Hub supported the integration of several of the previous systems by...

Note: Names and company names are presented for illustration purposes only 


\section{Zsófia Tóth et al.}

\section{Appendix 2}

Figure A2 A local network-of-references showing direction of references

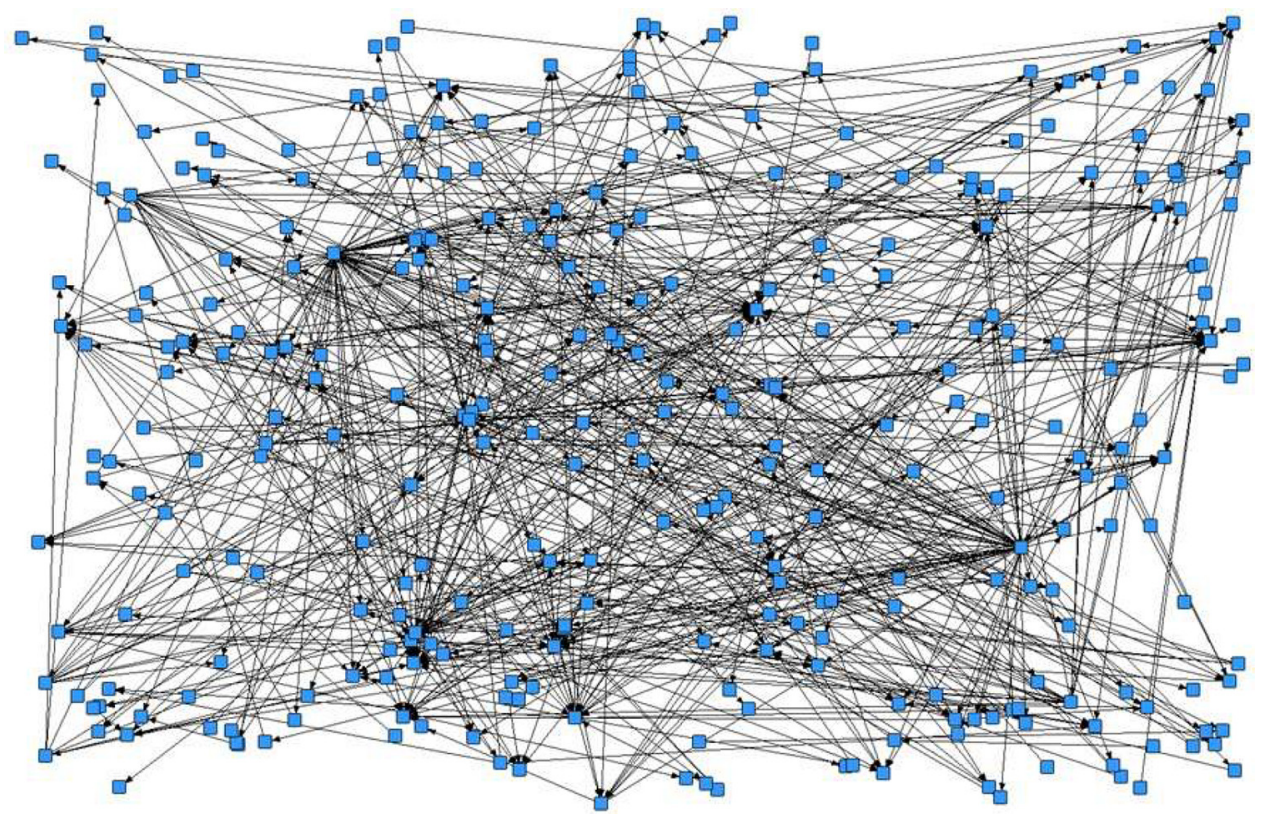

\section{Corresponding author}

Zsófia Tóth can be contacted at: Zsofia.Toth@nottingham. ac.uk 